"This document is the Accepted Manuscript version of a Published Work that appeared in final form in American Society for Mass Spectrometry, copyright (C) American Chemical Society after peer review and technical editing by the publisher. To access the final edited and published work see http://doi.org/10.1007/s13361-019-02134-5 " 


\title{
Evidence of Cis/Trans-Isomerization at Pro7/Pro16 in the Lasso
}

\section{Peptide Microcin J25}

\author{
Kevin Jeanne Dit Fouque, ${ }^{\dagger}$ Julian D. Hegemann, ${ }^{\ddagger}$ Séverine Zirah,§ Sylvie Rebuffat,§ \\ Ewen Lescop," and Francisco Fernandez-Lima *,† \\ ${ }^{\dagger}$ Department of Chemistry and Biochemistry, Florida International University, Miami, FL 33199, USA. \\ ${ }^{\ddagger}$ M Department of Chemistry, University of Illinois, Urbana-Champaign, IL 61801, USA. \\ $\S$ Laboratory Molecules of Communication and Adaptation of Microorganisms, National Museum of \\ Natural History, CNRS UMR 7245, 75005 Paris, France. \\ " Institut de Chimie des Substances Naturelles, CNRS UPR 2301, Université Paris-Saclay, 91198 Gif sur \\ Yvette Cedex, France.
}


Address reprint requests to Dr. Francisco Fernandez-Lima; Address: $11200 \mathrm{SW} 8^{\text {th }}$ St., AHC4-233, Miami, FL 33199, United States; Telephone: +1 305-348-2037; E-mail: fernandf@fiu.edu.

ABSTRACT

Microcin J25 is a ribosomal synthesized and post-translationally modified peptide (RiPP) characterized by a mechanically interlocked topology called the lasso fold. This structure provides microcin $\mathrm{J} 25$ a potent antimicrobial activity resulting from internalization via the siderophore receptor FhuA and further inhibition of the RNA polymerase. In the present work, nuclear magnetic resonance (NMR) and trapped ion mobility spectrometry - mass spectrometry (TIMS-MS) were used to investigate the lasso structure of microcin J25. NMR experiments showed that the lasso peptide microcin J25 can adopt conformational states where Pro16 can be found in the cis- and trans-orientations. The high-resolution mobility analysis, aided by site-directed mutagenesis $\left(\left[\mathrm{P}_{7} \mathrm{~A}\right],[\mathrm{P} 16 \mathrm{~A}]\right.$ and $\left[\mathrm{P}_{7 \mathrm{~A}} / \mathrm{P}_{16 \mathrm{~A}}\right]$ variants), demonstrated that microcin $\mathrm{J}_{25}$ can adopt cis/cis-, cis/trans-, trans/cis- and trans/trans-conformations at the Pro7 and Pro16 peptide bonds. It was also shown that interconversion between the conformers can occur as a function of the starting solvent conditions and ion heating (collision induced activation, CIA) despite the lasso topology. Complementary to NMR findings, the cis-conformations at Pro7 were assigned using TIMS-MS. This study highlights the analytical power of TIMS-MS and site-directed mutagenesis for the study of biological systems with large microheterogeneity as a way to further increase our understanding of the receptor binding dynamics and biological activity. 


\section{INTRODUCTION}

Lasso peptides form a structurally class of ribosomal synthesized and posttranslationally modified peptides (RiPPs) exhibiting a variety of biological activities, such as enzyme inhibition, receptor antagonism, antimicrobial or antiviral properties $[\mathbf{1}$, 2]. All lasso peptides are characterized by a unique mechanically interlocked topology in which the C-terminal tail is threaded through and trapped within an N-terminal macrolactam ring (Figure S1) [1-3]. This threaded fold is stabilized in the C-terminal tail region by steric hindrance, mediated by bulky amino acid side chains above and below the ring forming plugs, and/or by disulfide bonds leading to a compact [1] rotaxane type structure (Figure $\mathrm{S}_{1}$ ). The lasso peptide family is divided into four classes depending on the presence of one (class III) or two (class I) interlinked disulfide bonds, or one (class IV) handcuff disulfide bond, while the class II lasso peptides have no disulfide bond [4] (Figure S1). Their compact and interlocked structures provide lasso peptides with high resistance to chemical, proteolytic and thermal degradation [5-8]. Many lasso peptides were discovered through genome mining approaches and isolation of new lasso structures is still an active area of research $[4,6,9-12]$.

The mechanically interlocked topology of lasso peptides, together with their panel of biological activities makes them a promising scaffold for next generation drug design $[13,14]$. However, one limitation to the activity of lasso peptides is related to unthreading of the C-terminal part, a trend reported for certain lasso peptides, yielding the corresponding branched-cyclic topoisomers $[6-8,15]$. Thus, the discovery and design of new lasso peptides as potential drug candidates requires analytical tools capable of 
characterizing lasso peptides as well as differentiating them from their unthreaded branched-cyclic topoisomers.

Microcin J25 is a class II lasso peptide produced by Escherichia coli AY25 that exerts potent antimicrobial activity against Escherichia and Salmonella species, through import in the target bacteria upon interaction with the iron-siderophore receptor FhuA [16] and inhibition of the RNA polymerase [17]. Microcin J25 is composed of a macrolactam ring of 8 residues, a loop of 11 residues located above the ring and a Cterminal tail of 2 residues located below the ring (Scheme 1). Its C-terminal part is sterically trapped into the macrolactam ring by the Phe19 and Tyrzo residues located on each side of the ring (Scheme 1). Cleavage within the loop region of microcin J25, either in solution by enzymatic digestion $[5,18]$, or in the gas phase upon collision-induced dissociation (CID) [19-22] and electron capture/transfer dissociation (EC/TD) [21, 22], specifically generates mechanically interlocked species with associated $\mathrm{N}$-terminal and C-terminal fragments through the steric hindrance provided by the side chains of Pheig and Tyrzo residues. Nuclear magnetic resonance (NMR) is often employed to unambiguously characterize the threading of the $\mathrm{C}$-terminal tail through the macrolactam ring, which results in specific nuclear Overhauser effects (NOEs) between residues in the ring and tail [23]. On the basis of NMR and infrared multiple photon disociation (IRMPD) spectroscopy studies, it has been proposed that the lasso structure of microcin J25 is stabilized by hydrogen bonds, via short antiparallel $\beta$-sheets and an ionic hydrogen bond [19, 24]. However, the NMR approach requires relatively large amounts of samples and the analysis of mixtures with the branched-cyclic topoisomer is not straightforward. Ion mobility spectrometry - mass spectrometry (IMS-MS) serves as an alternative strategy to NMR for the differentiation between the lasso and branched- 
cyclic topologies of microcin $\mathrm{J} 25[25,26]$. It has been shown that highly charged protonated species $\left([\mathrm{M}+4 \mathrm{H}]^{4+}\right)$ of the the lasso and branched-cyclic structures, obtained using sulfolane supercharging reagent [27], can be separated using traveling wave ion mobility spectrometry (TWIMS, Figure S2), while lower charged protonated species $\left([\mathrm{M}+2 \mathrm{H}]^{2+}\right.$ and $\left.[\mathrm{M}+3 \mathrm{H}]^{3+}\right)$ yielded similar drift times $\left(t_{D}\right)$ distribution for both microcin J25 topoisomers $[25,26]$.

The push for higher resolution and more sensitivity IMS-MS has led, among others, to the development of trapped IMS-MS (TIMS-MS) [28-30]. TIMS-MS has been effective in a variety of bioanalytical studies, including small molecules [31, 32], peptides [33-35], proteins [36-38], DNA [39, 40], polymers [41], petroleomics [42], lipidomics [43] and proteomics $[44,45]$. Remarkable is the potential of TIMS for the separation of isomers in mixtures, due to the high mobility resolving power [46-48]. In a recent study, the potential of native nESI-TIMS-MS for high throughput screening of peptide topoisomers was illustrated for lasso peptides and their branched-cyclic analogs [49]. Moreover, the analytical advantages of metalation of lasso topoisomers has been demonstrated by efficiently turning the metal ion adduction into additional separation dimensions [50].

In the present work, the proline orientation (e.g., cis/trans at Pro7 and Pro16) and their possible interconversions in microcin J25 (Scheme 1) were studied as a function of the stating solvent condition using NMR, TIMS-MS and site directed mutagenesis ([P7A], [P16A] and $\left[\mathrm{P}_{7} \mathrm{~A} / \mathrm{P}_{16 \mathrm{~A}}\right]$ variants). The influence of the time after desolvation and the effect of ion heating (using collision induced activation, CIA) on the mobility profiles is described. 


\section{Microcin J25}
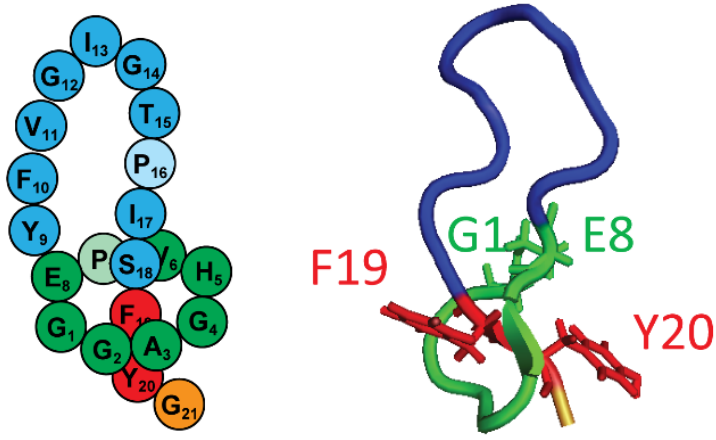

Scheme 1. Sequence and three-dimensional structure of microcin J25 (PDB 1Q71) [19]. The macrolactam ring is colored in green, the loop in blue, the plugs in red and the Cterminal tail in orange. The Pro7 and Pro16 residues, located in the ring and loop respectively, are pointed in lighter green and blue colors.

\section{EXPERIMENTAL}

\section{Materials and Reagents.}

Details on microcin J25 expression have been previously reported [51]. Briefly, Escherichia coli MC410o cells harboring the plasmid pTUC202 [52] were grown in M63 medium supplemented with $1 \mathrm{mg} / \mathrm{mL}$ vitamin $\mathrm{B} 1$, $0.02 \% \mathrm{MgSO}_{4}$, $0.02 \%$ glucose and $1 \mathrm{~g} / \mathrm{L}$ casamino acids at $37^{\circ} \mathrm{C}$ for $16 \mathrm{~h}$. For production of ${ }^{15} \mathrm{~N}$ labeled microcin J25, the culture medium contained $0.15 \%{ }^{15} \mathrm{~N}$-labeled ammonium sulfate (Eurisotop). Microcin J25 was purified from the culture supernatant by solid phase extraction using SepPak $C_{8}$ reversed-phase cartridges (Waters). The elution was performed using water with $0.1 \%$ formic acid and acetonitrile mixtures with increasing content of acetonitrile, and the fractions of interest were then evaporated under reduced pressure. A second purification 
step was performed by reversed-phase high performance liquid chromatography (HPLC).

The $\left[\mathrm{P}_{7} \mathrm{~A}\right],[\mathrm{P} 16 \mathrm{~A}]$ and $\left[\mathrm{P}_{7} \mathrm{~A} / \mathrm{P}_{16} \mathrm{~A}\right]$ variants of microcin $\mathrm{J}_{25}$ were produced by sitedirected mutagenesis on the plasmid pTUC202 using the Quick-Change II XL kit (Agilent) following the manufacturer's instructions. Briefly, the PCRs were carried out with PfuUltra High Fidelity DNA polymerase in an Eppendorf MasterCycler by the following program: initial denaturation at $95{ }^{\circ} \mathrm{C}$ for $1 \mathrm{~min}$, followed by 18 cycles of $95{ }^{\circ} \mathrm{C}$ for $50 \mathrm{~s}, 6 \mathrm{o}^{\circ} \mathrm{C}$ for $50 \mathrm{~s}, 68^{\circ} \mathrm{C}$ for $10 \mathrm{~min}$, and a final extension at $68^{\circ} \mathrm{C}$ for $7 \mathrm{~min}$. The PCR product was treated with DpnI for $1 \mathrm{~h}$ at $37^{\circ} \mathrm{C}$ and used to transform kanamycin-resistant Escherichia coli XL1o-Gold ultra-competent cells. The mutated sites were confirmed by DNA sequencing (Eurofins MWG Operon).

The peptides were dissolved in $10 \mathrm{mM} \mathrm{NH}_{4} \mathrm{Ac}$ in $100 \% \mathrm{H}_{2} \mathrm{O}$ to a $5 \mu \mathrm{M}$ final concentration. Sample solutions were also prepared with 5:95 (v/v) $\mathrm{H}_{2} \mathrm{O} / \mathrm{MeOH}$ mixtures for comparison with the NMR data. The instrument was externally calibrated using the Tuning Mix (Agilent, Santa Clara, CA) [30].

TIMS-MS Experiments. IMS-MS experiments were performed on a custom built nESI-TIMS unit coupled to an Impact Q-TOF mass spectrometer (Bruker, Billerica, MA) $[28,29]$. The TIMS unit is controlled using a custom software in LabView (National Instruments) synchronized with the MS platform controls [29]. Sample aliquots (10 $\mu \mathrm{L})$ were loaded in a pulled-tip capillary biased at 700-1300 V. Briefly, the ion mobility separation in a TIMS device is based on holding the ions stationary using an electric field (E) against a moving buffer gas [28, 29] (Figure S3). In TIMS operation, multiple conformers are trapped simultaneously at different $E$ values resulting from a voltage 
gradient applied across the IMS tunnel region (Figure S3). Ions are eluted from the TIMS

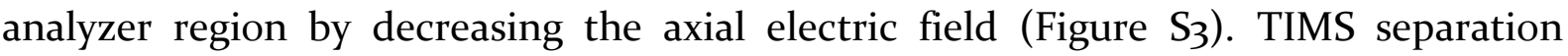
depends on the gas flow velocity $\left(v_{g}\right)$, elution voltage $\left(V_{\text {elution }}\right)$, ramp time $\left(t_{\text {ramp }}\right)$ and base voltage $\left(V_{\text {out }}\right)[28,53]$. The mobility, $K_{o}$, is defined by:

$K_{0}=\frac{v_{g}}{E} \approx \frac{A}{\left(V_{\text {elution }}-V_{\text {out }}\right)}$

The constant $A$ was determined using known reduced mobilities of Tuning Mix components [30]. The measured mobilities were converted into collision cross sections (CCS, $\left.\AA^{2}\right)$ using the Mason-Schamp equation:

$\Omega=\frac{(18 \pi)^{1 / 2}}{16} \frac{q}{\left(k_{B} T\right)^{1 / 2}}\left(\frac{1}{m}+\frac{1}{M}\right)^{1 / 2} \frac{1}{N} \times \frac{1}{K}$

where $q$ is the ion charge, $k_{B}$ is the Boltzmann constant, $N$ is the gas number density, $m$ is the ion mass, and $M$ is the gas molecule mass [53].

The TIMS-MS experiments were performed using nitrogen $\left(\mathrm{N}_{2}\right)$ as buffer gas at room temperature $(T)$. The $v_{g}$ is defined by the pressure difference between the funnel entrance $\left(\mathrm{P}_{1}=2.6 \mathrm{mbar}\right)$ and funnel exit $\left(\mathrm{P}_{2}=1.1 \mathrm{mbar}\right.$, Figure $\left.\mathrm{S}_{3}\right)$. An rf voltage of 250 $\mathrm{V}_{\mathrm{pp}}$ at $88 \mathrm{o} \mathrm{kHz}$ was applied to all electrodes. Separations were performed using a voltage ramp $\left(V_{\text {ramp }}\right)$ of -20o to -5o $\mathrm{V}$ and base voltage $\left(V_{\text {out }}\right)$ of $60 \mathrm{~V}$. TIMS spectra were collected for $t_{\text {ramp }}=100-500 \mathrm{~ms}$. Ion heating experiments (collision induced activation, CIA) were performed by changing the electric potential on the capillary outlet $\left(V_{\text {cap }}\right)$ from 40 at 280 $\mathrm{V}$ and the deflector plate $\left(V_{d e f}\right)$ from 60 to $300 \mathrm{~V}$, while maintaining the funnel In $\left(V_{\text {fun }}\right)$ at o $\mathrm{V}$ (Figure $\mathrm{S}_{3}$ ). The mobility resolving power $(R)$ is defined as $R=\mathrm{CCS} / w$, where $w$ is the full peak width at half maximum (FWHM). 
Correction of Pro substituted collision cross sections. Direct comparison of the mobility profiles between the lasso peptide microcin $\mathrm{J}_{25}$ and the $\left[\mathrm{P}_{7} \mathrm{~A}\right],[\mathrm{P} 16 \mathrm{~A}]$ and $\left[\mathrm{P}_{7} \mathrm{~A} / \mathrm{P} 16 \mathrm{~A}\right]$ variants was done by adjusting the CCS profiles based on a methodology previously described [54-57]. Differences in CCS between $\mathrm{N}_{2}$ and He were adjusted using the $\mathrm{CCS}_{\mathrm{N}_{2}}=1.0857\left(\mathrm{CCS}_{\mathrm{He}}\right)+81.459\left[\AA^{2}\right]$ equation $[58,59]$. This resulted in Pro to Ala substitutions to be corrected by $2.68 \AA^{2}$ in $\mathrm{N}_{2}$.

NMR Experiments. An NMR study for microcin J25 in aqueous solution was recently published [6o]. The NMR spectra of ${ }^{15} \mathrm{~N}$ labeled microcin $\mathrm{J}_{25}$ in $100 \% \mathrm{CD}_{3} \mathrm{OH}$ were collected on a Bruker Avance II $700 \mathrm{MHz}$ spectrometer equipped with a roomtemperature triple ressonance probe (TXI). The assignment of the most intense cross peaks from the ${ }^{15} \mathrm{~N}$ band-selective excitation short transient - heteronuclear single quantum correlation (BEST-HSQC) spectrum was facilitated by the available assignment of the peptide in similar conditions [61] and adjusted from newly collected 2D total correlation spectroscopy (TOCSY) and nuclear Overhauser effect spectroscopy (NOESY) spectra.

\section{RESULTS AND DISCUSSION}

The analysis of the lasso peptide microcin J25 under native conditions resulted in the observation of a single charge state species $\left([\mathrm{M}+2 \mathrm{H}]^{2+}\right.$ ) (Figure 1 , with metrics for the CCS and $R$ listed in Table $\mathrm{S}_{1}$ ). The mobility profile of the $[\mathrm{M}+2 \mathrm{H}]^{2+}$ microcin $\mathrm{J}_{25} \mathrm{WT}$ can be described as a broad IMS distribution containing a large number of IMS bands, ranging from $473^{-515} \AA^{2}$, even for the relatively compact lasso topology [49]. While previous experiments on microcin J25 using TWIMS technology showed a single broad IMS distribution (Figure 1 dashed line, $R \sim 20$ ) [25], a higher number of IMS bands and 
features can be observed using TIMS analysis with a scan rate of $S r=0.3-1.5 \mathrm{~V} / \mathrm{ms}$ (Figure 1 color line). Beside the expected increase in mobility resolution with the trapping time increase (decreasing the Sr), no changes in the relative abundances of the IMS bands were observed between 100-500 ms (Figure $\mathrm{S}_{4}$ ). The TIMS distribution for microcin J25 can be divided in two regions: i) two IMS bands centered at 473 and $478 \AA^{2}$, and ii) multiple IMS bands centered from $486-515 \AA^{2}$. The observation of multiple IMS bands is a consequence of multiple tertiary structures of microcin J25 stabilized by distinct combinations of intramolecular interactions as previously described [49].

\section{Microcin J25: $[\mathrm{M}+2 \mathrm{H}]^{2+}$}

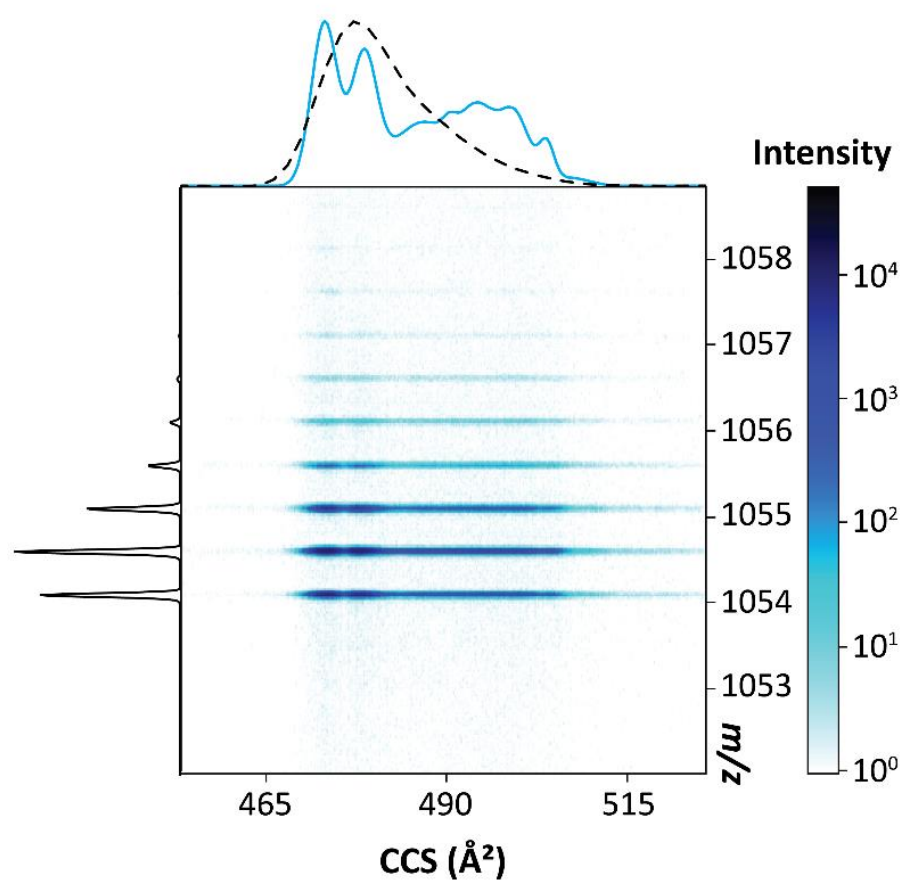

Figure 1. 2D-TIMS-MS contour map of the doubly protonated species of the lasso peptide microcin J25 WT under native conditions and no ion heating. The black dashed line illustrates a previously reported TWIMS distribution [25].

\section{Evidence of cis/trans-isomerization at Pro16 in NMR}


In a recent NMR study, microcin J25 was studied in aqueous solution [6o]. It was equilibrium of 10/9o of the Thr15-Pro16 peptide bond in aqueous solution [6o]. When the microcin $\mathrm{J} 25$ was studied in methanol $\left(\mathrm{CD}_{3} \mathrm{OH}\right)$ using ${ }^{15} \mathrm{~N}$ BEST-HSQC (highlighted in blue in Figure 2), two sets of cross peaks were clearly observed: one set of strong cross peaks corresponding to the trans-conformation at Pro16 (most populated conformation) and a second set corresponding to the cis-conformation of Pro16 (weaker in intensity). In addition, the 2D ZZ-exchange spectrum (highlighted in red in Figure 2) showed that the two states are in exchange at the sub-second timescale. The residues showing significant chemical shift variations between the two states were the same as observed in water [6o]. Assuming similar relaxation properties for the ${ }^{1} \mathrm{H} /{ }^{15} \mathrm{~N}$ spins of the same residue in the two states and on the basis of the relative cross-peak intensity in the HSQC spectra, we could estimate the cis/trans-equilibrium to 5/95 in methanol solution. Although the cis-conformation is slightly disfavored in methanol solution, as compared to the aqueous solution, the cis/trans-isomerization is still preserved. 
Microcin J25

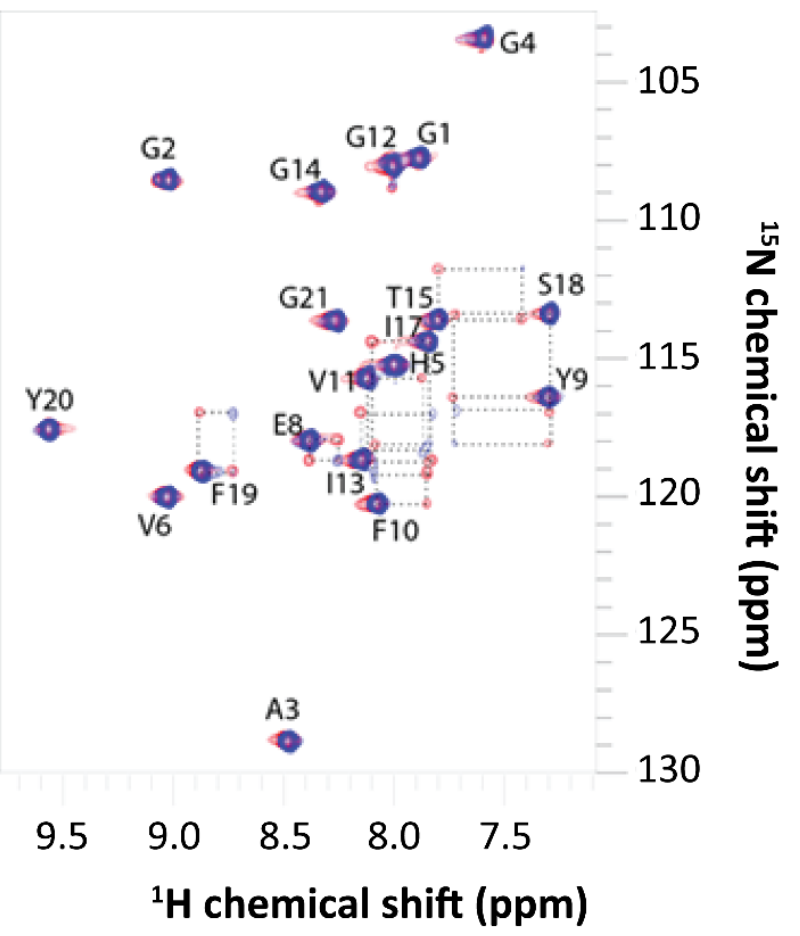

Figure 2. The ${ }^{15} \mathrm{~N}$ HSQC spectrum of ${ }^{15} \mathrm{~N}$ labeled microcin $\mathrm{J}_{25}$ in $\mathrm{CD}_{3} \mathrm{OH}$ is shown in blue. The spectrum shown in red is a ZZ-exchange spectrum with a mixing time of 600 ms. For clarity, the weak cross peaks corresponding to the minor conformation (cis) are not labeled.

\section{Evidence of cis/trans-isomerization at Pro7/Pro16 in TIMS}

In order to evaluate the influence of the cis- and trans-orientations at Pro7 and Pro16 residues on the microcin J25 tertiary structure, we substituted Pro 7 and Pro16 by Ala to generate the $\left[\mathrm{P}_{7} \mathrm{~A}\right],[\mathrm{P} 16 \mathrm{~A}]$ and $\left[\mathrm{P}_{7} \mathrm{~A} / \mathrm{P} 16 \mathrm{~A}\right]$ variants. These single and double mutants in combination with IMS-MS allow for the possibility to identify the orientation of the prolines (i.e., cis/trans-orientation) by direct comparison of the corrected IMS profiles [54]. Prolines in the trans-orientation are required to overcome a $\sim 13 \mathrm{kcal} / \mathrm{mol}$ energy barrier in order to convert to the cis-orientation position (the trans-state is $\sim 0.5$ 
$\mathrm{kcal} / \mathrm{mol}$ lower in energy than the cis-form) [62]. However, alanine residues (not bound to proline) are energetically more favorable in the trans-orientation (the trans-state is $\sim 2.5 \mathrm{kcal} / \mathrm{mol}$ lower in energy with a trans to cis $\sim 20 \mathrm{kcal} / \mathrm{mol}$ barrier [62]. The proline state in the microcin J25 WT is determined by direct comparison of the mobility profiles of the microcin $\mathrm{J}_{25} \mathrm{WT}$ relative to the $\left[\mathrm{P}_{7} \mathrm{~A}\right],[\mathrm{P} 16 \mathrm{~A}]$ and $\left[\mathrm{P}_{7} \mathrm{~A} / \mathrm{P} 16 \mathrm{~A}\right]$ variants; conservation and absence of an IMS band in the variants determine that the WT proline orientation is trans and cis, respectively [54]. Thus, comparison of the corrected TIMS profiles for the microcin $\mathrm{J}_{25} \mathrm{WT}$ and the $[\mathrm{P} 7 \mathrm{~A}]$, $[\mathrm{P} 16 \mathrm{~A}]$ and $\left[\mathrm{P}_{7} \mathrm{~A} / \mathrm{P} 16 \mathrm{~A}\right]$ variants permits the assignment of the proline orientations in the native microcin J25 WT (Figure 3 and Table 1).

Distinct TIMS profile were observed for the microcin $J_{25} \mathrm{WT}$ relative to the $\left[\mathrm{P}_{7} \mathrm{~A}\right]$, $[\mathrm{P} 16 \mathrm{~A}]$ and $\left[\mathrm{P}_{7} \mathrm{~A} / \mathrm{P} 16 \mathrm{~A}\right]$ variants (Figure 3a). While nine IMS bands were observed for microcin J25 WT in native conditions, a reduced number of IMS bands was observed for the variants. These results suggest that most of the structural heterogeneity of microcin J25 is driven by the Pro7 and Pro16 cis/trans-isomerization. Closer inspection shows that IMS bands 1 and 2 of microcin J25 WT were common with the $\left[\mathrm{P}_{7} \mathrm{~A}\right]$ and $[\mathrm{P} 16 \mathrm{~A}]$ variants, indicating that these IMS bands have at least one proline (Pro7 or Pro16) in cisconformation while the other proline (Pro7 or Pro16) is in trans-conformation (Figure 3a). This is supported by the absence of the IMS bands 1 and 2 in the TIMS distribution of the $\left[\mathrm{P}_{7} \mathrm{~A} / \mathrm{P} 16 \mathrm{~A}\right]$ double variant for which only trans-conformations are expected (Figure 3a). In addition, different relative abundance were observed for the IMS bands 1 and 2 when compared the $\left[\mathrm{P}_{7} \mathrm{~A}\right]$ and $[\mathrm{P} 16 \mathrm{~A}]$ variants. This could be explained by the presence of the Pro7 in cis-conformation, located in the macrolactam ring, for the [P16A] variant that will have a significant impact on the loop region by extending this region 
thus disfavoring the more compact conformations. By contrast, the presence of the Pro16 in cis-conformation, located in the loop, for the $\left[\mathrm{P}_{7} \mathrm{~A}\right]$ variant will have less impact on the loop region because of the flexibility of this part of microcin J 25 by promoting the more compact conformation. Thus, these observations suggest that the Pro16 in cisconformation probably drive the IMS bands 1 and 2 (Figure 3a).

Changes in the relative abundances of the IMS bands 3 and 4 were found between the microcin J25 WT, $\left[\mathrm{P}_{7} \mathrm{~A}\right]$ and $[\mathrm{P} 16 \mathrm{~A}]$ variants (Figure 3a). These changes are characterized by the Pro7 in trans-conformation and and the Pro16 cis-conformation in IMS bands 3 and Pro7 in cis-conformation and the Pro16 in trans-conformation in IMS band 4. Furthermore, the TIMS distribution of the $\left[\mathrm{P}_{7} \mathrm{~A} / \mathrm{P} 16 \mathrm{~A}\right]$ double variant exhibited a single IMS band (5) corresponding to trans/trans-conformations arising from the two alanine residues (Figure 3a). The presence of a single band for the $\left[\mathrm{P}_{7} \mathrm{~A} / \mathrm{P} 16 \mathrm{~A}\right]$ double variant suggests that in IMS band 5 the two prolines do not carry the charge. In the events where only one proline is substituted, a competition in the proton attachment probably occurs among the most basic residues leading to the formation of protomers.

The IMS band 6 has a similar variation as those of IMS bands 1 and 2 showing the existence of at least one of the prolines in a cis-conformation while the other is in a transconformation. The IMS band 7 was found unique for the native microcin J25 (Figure 3a). This suggests that the IMS band 7 is specific for Pro7 and Pro16 in cis/cis-conformation. The observation of an extended cis/cis-conformation is also consistent with the previous observation for which the cis-conformation of the Pro7 showed an elongation of the loop region of the lasso peptide microcin J25. Finally, the IMS bands 8 and 9 were found unique for the $[\mathrm{P} 16 \mathrm{~A}]$ variant (Figure 3a). This strongly suggests that the IMS bands 8 and 9 are 
specific for Pro7 in cis-conformation. The IMS bands 8 and 9 were in lower relative abundance for the native microcin J25 WT when compared to the P16 variant, suggesting that the Pro7 in cis-conformation stabilizes some of the more extended structures.
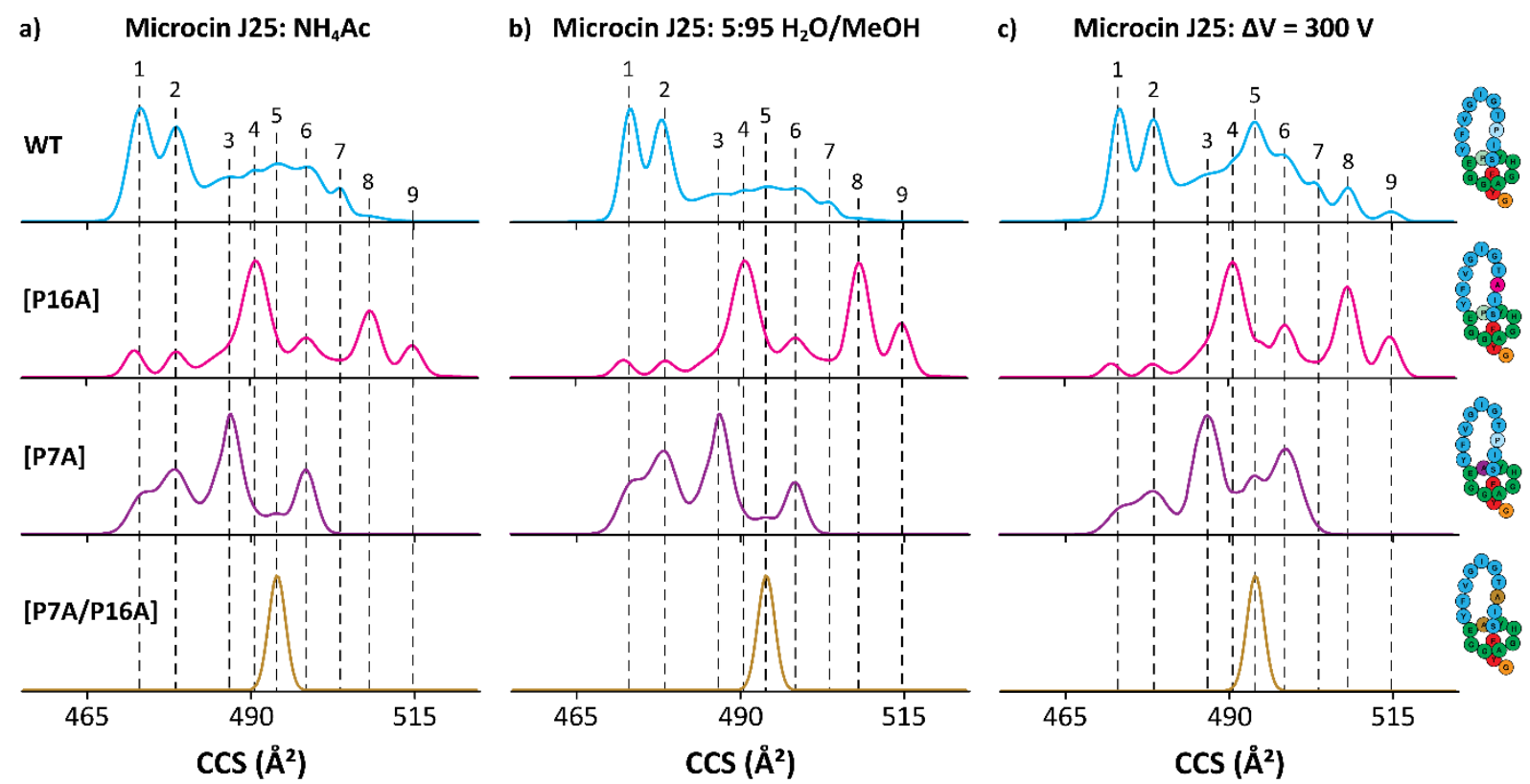

Figure 3. High resolution TIMS spectra for the $[\mathrm{M}+2 \mathrm{H}]^{2+}$ ions of microcin J25 (blue trace), the $[\mathrm{P} 16 \mathrm{~A}]$ variant (magenta trace), the $\left[\mathrm{P}_{7} \mathrm{~A}\right]$ variant (purple trace) and the $\left[\mathrm{P}_{7} \mathrm{~A} / \mathrm{P} 16 \mathrm{~A}\right]$ double variant (gold trace) in a) native condition $\left(\mathrm{NH}_{4} \mathrm{Ac}\right)$, denaturing condition (5:95 $\mathrm{H}_{2} \mathrm{O} / \mathrm{MeOH}$ ) and c) with an activation energy of $\Delta \mathrm{V}=300 \mathrm{~V} . \Delta \mathrm{V}$ represents the voltage difference between $V_{\text {def }}$ and $V_{\text {fun }}$ (Figure $S_{3}$ ). The single and double mutant CCS profiles have been corrected for a better IMS band comparison.

The TIMS results are in agreement with the NMR experiments, for which two populations corresponding to cis/trans-conformations at the Pro16 residue were observed in aqueous solution [55]. Nevertheless, NMR experiments were not able to assign Pro7 in a cis-conformation probably because the trans-conformations are largely predominant in aqueous solution (90\%) combining with the ability of the Pro16 in cisconformation to drive the conformation of the microcin J25 WT. 
Table 1. Summary of proline cis/trans-configuration at Pro7 and Pro16 peptide bonds of the native microcin J25 WT per IMS band (1-9).

\begin{tabular}{lll}
\hline \multirow{2}{*}{ IMS bands } & \multicolumn{2}{l}{ cis/trans-configurations } \\
& Pro7 & Pro16 \\
\hline 1 & cis/trans & trans/cis \\
2 & cis/trans & trans/cis \\
3 & trans & cis \\
4 & cis & trans \\
5 & trans & trans \\
6 & cis/trans & trans/cis \\
7 & cis & cis \\
8 & cis & trans \\
9 & cis & trans \\
\hline
\end{tabular}

\section{Changes in conformational distribution as a function of starting solvent condition and ion heating}

In addition to native starting solvent conditions, TIMS-MS experiments in 5:95 $\mathrm{H}_{2} \mathrm{O} / \mathrm{MeOH}$ starting solvent condition were considered to identify potential differences in the molecular environment of microcin J25 and its variants, which could be associated with rearrangements and changes in the relative abundance of the cis/trans-conformers (Figure $3 \mathrm{~b}$ ). The TIMS spectra of the microcin J25 WT and the $\left[\mathrm{P}_{7} \mathrm{~A}\right]$ variant at 5:95 $\mathrm{H}_{2} \mathrm{O} / \mathrm{MeOH}$ solvent composition showed a similar TIMS distribution with differences in the relative abundance of IMS bands, where the most compact structures (IMS bands 1 and 2) are more favored in 5:95 $\mathrm{H}_{2} \mathrm{O} / \mathrm{MeOH}$ solvent composition (Figure $3 \mathrm{~b}$ ). In addition, a relative increase in the most extended structures (IMS bands 8 and 9) and a slightly relative decrease in the most compact structures (IMS bands 1 and 2) were observed for the TIMS [P16A] variant profile in 5:95 $\mathrm{H}_{2} \mathrm{O} / \mathrm{MeOH}$ solvent composition (Figure $3 \mathrm{~b}$ ). These changes in the relative abundances of the IMS profiles as a function of the starting 
solvent conditions evidence that there is a "memory effect" on the observed IMS profiles despite the lasso topology, and that the organic content can significantly change the equilibria (and relative abundances) between the cis- and trans-conformers; similar trends have been previously reported in other systems [54, 63]. Interestingly, changes in the TIMS distribution of the $\left[\mathrm{P}_{7} \mathrm{~A} / \mathrm{P}_{16} \mathrm{~A}\right]$ double variant were not observed as a function of the starting solvent conditions (Figure $3 \mathrm{~b}$ ). While the Pro/Ala substitution will suggest a larger backbone flexibility, the nature of the lasso peptide and the charge location seems to largely stabilize the microcin $\mathrm{j}_{25}\left[\mathrm{P}_{7 \mathrm{~A}} / \mathrm{P}_{16 \mathrm{~A}}\right]$ variant. The TIMS observations are consistent and complementary to the NMR data, where cis/trans-conformations at the Pro7 and Pro16 residues are present in microcin J25 in methanol.

The ion heating influence on the conformational space of microcin J25 WT and the $\left[\mathrm{P}_{16} \mathrm{~A}\right],\left[\mathrm{P}_{7} \mathrm{~A}\right]$, and $\left[\mathrm{P}_{7} \mathrm{~A} / \mathrm{P}_{16} \mathrm{~A}\right]$ variants was performed using collision induced activation (CIA) prior to the TIMS-MS analysis (Figure 3c). The energy from collisions can allow to overcome conformational barriers and sample other local free energy minima not amenable by changes in the molecular environment by varying the starting solvent conditions [64-67]. While the same number of IMS bands was observed at $\Delta \mathrm{V}=$ $300 \mathrm{~V}$, changes in the relative abundance of IMS bands were observed. For example, a larger abundance of more extended conformations is observed (IMS bands 5, 6, 8 and 9) after CIA. In the case of the IMS bands 5 and 6 , the higher relative abundances in the native microcin J25 comes from isomerization of structures with Pro7/Pro16 in cisorientation towards trans-orientation during CIA, as evidence from the comparison with the $[\mathrm{P} 16 \mathrm{~A}] /\left[\mathrm{P}_{7} \mathrm{~A}\right]$ IMS profiles. Increasing the activation energy also favors the most extended conformations of the peptide as reflected by the IMS bands 8 and 9, for which higher abundances in the microcin J25 WT are observed involving the Pro7 in cis- 
orientation that induces an extending of the loop region. In addition, the TIMS distribution for the $\left[\mathrm{P}_{7} \mathrm{~A} / \mathrm{P}_{16} \mathrm{~A}\right]$ double variant showed no changes upon $\mathrm{CIA}$. This result also confirms that the nature of the lasso peptide and the charge location seems to largely

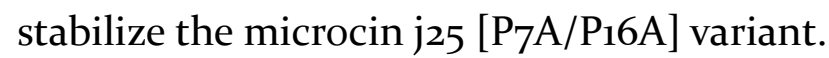

\section{CONCLUSION}

The use of NMR and high-resolution mobility, in combination with site-directed mutagenesis permitted the study of the cis/trans-isomerization dynamics of microcin J25 as a function of the starting solvent condition and CIA. An agreement was observed between the NMR and the TIMS-MS findings, where Pro16 exists in the cis- and transorientations. Nine mobility bands were observed for the microcin J25 under native conditions, with varying proline cis/trans-orientations. Aided by comparisons of the IMS profiles between the microcin $J_{25} \mathrm{WT}$ and the $\left[\mathrm{P}_{7} \mathrm{~A}\right],[\mathrm{P} 16 \mathrm{~A}]$ and $\left[\mathrm{P}_{7} \mathrm{~A} / \mathrm{P}_{16} \mathrm{~A}\right]$ variants, the Pro7 and Pro16 cis/trans-orientations were determined. It was demonstrated that the lasso topology of microcin J25 can adopt cis/cis-, cis/trans-, trans/cis- and trans/transconformations at the Pro7 and Pro16 peptide bonds. It was also shown that interconversion between the conformers can occur as a function of the starting solvent conditions and CIA, despite the lasso topology. Complementary to NMR findings, the cis-conformations at Pro7 were assigned using TIMS-MS. This study highlights the analytical power of TIMS-MS and site-directed mutagenesis for the study of biological systems with large micro-heterogeneity as a way to further increase our understanding of the receptor binding dynamics and biological activity.

\section{ACKNOWLEDGMENTS}


The work at FIU was supported by a NSF CAREER (CHE-1654274), with co-funding from by the ANR grant LASSO (BLAN-NTo9-692063).

\section{REFERENCES}

1. Hegemann, J.D., Zimmermann, M., Xie, X., Marahiel, M.A.: Lasso peptides: an intriguing class of bacterial natural products. Acc. Chem. Res. 48, 1909-1919 (2015)

2. Maksimov, M.O., Pan, S.J., James Link, A.: Lasso peptides: structure, function, biosynthesis, and engineering. Nat. Prod. Rep. 29, 996-1006 (2012)

3. Li, Y., Zirah, S., Rebuffat, S.: Lasso Peptides: Bacterial Strategies to Make and Maintain Bioactive Entangled Scaffolds. Springer, New York (2015)

4. Tietz, J.I., Schwalen, C.J., Patel, P.S., Maxson, T., Blair, P.M., Tai, H.C., Zakai, U.I., Mitchell, D.A.: A new genome-mining tool redefines the lasso peptide biosynthetic landscape. Nat. Chem. Biol. 13, 470-478 (2017)

5. $\quad$ Ducasse, R., Yan, K.P., Goulard, C., Blond, A., Li, Y., Lescop, E., Guittet, E., Rebuffat, S., Zirah, S.: Sequence determinants governing the topology and biological activity of a lasso peptide, microcin J25. ChemBioChem. 13, 371-380 (2012)

6. Hegemann, J.D., Zimmermann, M., Zhu, S., Klug, D., Marahiel, M.A.: Lasso peptides from proteobacteria: Genome mining employing heterologous expression and mass spectrometry. Biopolymers. 100, 527-542 (2013)

7. Zimmermann, M., Hegemann, J.D., Xie, X., Marahiel, M.A.: The astexin-1 lasso peptides: biosynthesis, stability, and structural studies. Chem. Biol. 2o, 558-569 (2013)

8. Hegemann, J.D., Fage, C.D., Zhu, S., Harms, K., Di Leva, F.S., Novellino, E., Marinelli, L., Marahiel, M.A.: The ring residue proline 8 is crucial for the thermal stability of the lasso peptide caulosegnin II. Mol. Biosyst. 12, 1106-1109 (2016) 
9. Hegemann, J.D., Zimmermann, M., Xie, X., Marahiel, M.A.: Caulosegnins I-III: a highly diverse group of lasso peptides derived from a single biosynthetic gene cluster. J. Am. Chem. Soc. 135, 210-222 (2013)

10. Maksimov, M.O., Link, A.J.: Prospecting genomes for lasso peptides. J. Ind. Microbiol. Biotechnol. 41, 333-344 (2014)

11. Maksimov, M.O., Pelczer, I., Link, A.J.: Precursor-centric genome-mining approach for lasso peptide discovery. Proc. Natl. Acad. Sci. USA. 109, 15223-15228 (2012)

12. Kersten, R.D., Yang, Y.L., Xu, Y., Cimermancic, P., Nam, S.J., Fenical, W., Fischbach, M.A., Moore, B.S., Dorrestein, P.C.: A mass spectrometry-guided genome mining approach for natural product peptidogenomics. Nat. Chem. Biol. 7, 794-802 (2011)

13. Knappe, T.A., Manzenrieder, F., Mas-Moruno, C., Linne, U., Sasse, F., Kessler, H., Xie, X., Marahiel, M.A.: Introducing lasso peptides as molecular scaffolds for drug design: engineering of an integrin antagonist. Angew. Chem. Int. Ed. Engl. 5o, 8714-8717 (2011)

14. Hegemann, J.D., De Simone, M., Zimmermann, M., Knappe, T.A., Xie, X., Di Leva, F.S., Marinelli, L., Novellino, E., Zahler, S., Kessler, H., Marahiel, M.A.: Rational improvement of the affinity and selectivity of integrin binding of grafted lasso peptides. J. Med. Chem. $57,5829-5834(2014)$

15. Knappe, T.A., Linne, U., Robbel, L., Marahiel, M.A.: Insights into the biosynthesis and stability of the lasso peptide capistruin. Chem. Biol. 16, 1290-1298 (2009)

16. Destoumieux-Garzon, D., Duquesne, S., Peduzzi, J., Goulard, C., Desmadril, M., Letellier, L., Rebuffat, S., Boulanger, P.: The iron-siderophore transporter FhuA is the receptor for the antimicrobial peptide microcin J25: role of the microcin Val11-Pro16 beta-hairpin region in the recognition mechanism. Biochem. J. 389, 869-876 (2005)

17. Mukhopadhyay, J., Sineva, E., Knight, J., Levy, R.M., Ebright, R.H.: Antibacterial peptide microcin $\mathrm{J}_{25}$ inhibits transcription by binding within and obstructing the RNA polymerase secondary channel. Mol. Cell. 14, 739-751 (2004) 
18. Rosengren, K.J., Blond, A., Afonso, C., Tabet, J.C., Rebuffat, S., Craik, D.J.: Structure of thermolysin cleaved microcin J25: extreme stability of a two-chain antimicrobial peptide devoid of covalent links. Biochemistry. 43, 4696-4702 (2004)

19. Rosengren, K.J., Clark, R.J., Daly, N.L., Goeransson, U., Jones, A., Craik, D.J.: Microcin J25 Has a Threaded Sidechain-to-Backbone Ring Structure and Not a Head-to-Tail Cyclized Backbone. J. Am. Chem. Soc. 125, 12464-12474 (2003)

2o. Wilson, K.-A., Kalkum, M., Ottesen, J., Yuzenkova, J., Chait, B.T., Landick, R., Muir, T., Severinov, K., Darst, S.A.: Structure of Microcin J25, a Peptide Inhibitor of Bacterial RNA Polymerase, is a Lassoed Tail. J. Am. Chem. Soc. 125, 12475-12483 (2003)

21. Zirah, S., Afonso, C., Linne, U., Knappe, T.A., Marahiel, M.A., Rebuffat, S., Tabet, J.-C.: Topoisomer Differentiation of Molecular Knots by FTICR MS: Lessons from Class II Lasso Peptides. J. Am. Soc. Mass Spectrom. 22, 467-479 (2011)

22. Jeanne Dit Fouque, K., Lavanant, H., Zirah, S., Hegemann, J.D., Fage, C.D., Marahiel, M.A., Rebuffat, S., Afonso, C.: General rules of fragmentation evidencing lasso structures in CID and ETD. Analyst. 143, 1157-1170 (2018)

23. Xie, X., Marahiel, M.A.: NMR as an Effective Tool for the Structure Determination of Lasso Peptides. ChemBioChem. 13, 621-625 (2012)

24. Jeanne Dit Fouque, K., Lavanant, H., Zirah, S., Steinmetz, V., Rebuffat, S., Maitre, P., Afonso, C.: IRMPD Spectroscopy: Evidence of Hydrogen Bonding in the Gas Phase Conformations of Lasso Peptides and their Branched-Cyclic Topoisomers. J. Phys. Chem. A. 120, $3810-3816(2016)$

25. Jeanne Dit Fouque, K., Afonso, C., Zirah, S., Hegemann, J.D., Zimmermann, M., Marahiel, M.A., Rebuffat, S., Lavanant, H.: Ion mobility-mass spectrometry of lasso peptides: signature of a rotaxane topology. Anal. Chem. 87, 1166-1172 (2015)

26. Fouque, K.J., Lavanant, H., Zirah, S., Hegemann, J.D., Zimmermann, M., Marahiel, M.A., Rebuffat, S., Afonso, C.: Signatures of Mechanically Interlocked Topology of Lasso 
Peptides by Ion Mobility-Mass Spectrometry: Lessons from a Collection of

27. Lomeli, S.H., Peng, I.X., Yin, S., Loo, R.R., Loo, J.A.: New reagents for increasing ESI multiple charging of proteins and protein complexes. J. Am. Soc. Mass Spectrom. 21, 127$131(2010)$

28. Fernandez-Lima, F.A., Kaplan, D.A., Suetering, J., Park, M.A.: Gas-phase separation using a Trapped Ion Mobility Spectrometer. Int. J. Ion Mobil. Spectrom. 14, 93-98 (2011)

29. Fernandez-Lima, F.A., Kaplan, D.A., Park, M.A.: Note: Integration of trapped ion mobility spectrometry with mass spectrometry. Rev. Sci. Instr. 82, 126106 (2011)

3o. Hernandez, D.R., Debord, J.D., Ridgeway, M.E., Kaplan, D.A., Park, M.A., FernandezLima, F.: Ion dynamics in a trapped ion mobility spectrometer. Analyst. 139, 1913-1921 (2014)

31. McKenzie-Coe, A., DeBord, J.D., Ridgeway, M., Park, M., Eiceman, G., Fernandez-Lima, F.: Lifetimes and stabilities of familiar explosive molecular adduct complexes during ion mobility measurements. Analyst. 140, 5692-5699 (2015)

32. Adams, K.J., Smith, N.F., Ramirez, C.E., Fernandez-Lima, F.: Discovery and targeted monitoring of polychlorinated biphenyl metabolites in blood plasma using LC-TIMSTOF MS. Int. J. Mass Spectrom. 427, 133-140 (2018)

33. Garabedian, A., Benigni, P., Ramirez, C.E., Baker, E.S., Liu, T., Smith, R.D., FernandezLima, F.: Towards Discovery and Targeted Peptide Biomarker Detection Using nanoESITIMS-TOF MS. J. Am. Soc. Mass Spectrom. 29, 817-826 (2017)

34. Jeanne Dit Fouque, K., Salgueiro, L.M., Cai, R., Sha, W., Schally, A.V., Fernandez-Lima, F.: Structural Motif Descriptors as a Way To Elucidate the Agonistic or Antagonistic Activity of Growth Hormone-Releasing Hormone Peptide Analogues. ACS Omega. 3, $7432-7440(2018)$ 
35. Silveira, J.A., Ridgeway, M.E., Park, M.A.: High resolution trapped ion mobility spectrometery of peptides. Anal. Chem. 86, 5624-5627 (2014)

36. Benigni, P., Marin, R., Molano-Arevalo, J.C., Garabedian, A., Wolff, J.J., Ridgeway, M.E., Park, M.A., Fernandez-Lima, F.: Towards the Analysis of High Molecular Weight Proteins and Protein complexes using TIMS-MS. Int. J. Ion Mobil. Spectrom. 19, 95-104 (2016)

37. Molano-Arevalo, J.C., Jeanne Dit Fouque, K., Pham, K., Miksovska, J., Ridgeway, M.E., Park, M.A., Fernandez-Lima, F.: Characterization of Intramolecular Interactions of Cytochrome c Using Hydrogen-Deuterium Exchange-Trapped Ion Mobility Spectrometry-Mass Spectrometry and Molecular Dynamics. Anal. Chem. 89, 8757-8765 $(2017)$

38. Liu, F.C., Ridgeway, M.E., Park, M.A., Bleiholder, C.: Tandem trapped ion mobility spectrometry. Analyst. 143, 2249-2258 (2018)

39. Garabedian, A., Butcher, D., Lippens, J.L., Miksovska, J., Chapagain, P.P., Fabris, D., Ridgeway, M.E., Park, M.A., Fernandez-Lima, F.: Structures of the kinetically trapped imotif DNA intermediates. Phys. Chem. Chem. Phys. 18, 26691-26702 (2016)

40. Garabedian, A., Bolufer, A., Leng, F., Fernandez-Lima, F.: Peptide Sequence Influence on the Conformational Dynamics and DNA binding of the Intrinsically Disordered ATHook 3 Peptide. Sci. Rep. 8, 10783 (2018)

41. Haler, J.R.N., Massonnet, P., Chirot, F., Kune, C., Comby-Zerbino, C., Jordens, J., Honing, M., Mengerink, Y., Far, J., Dugourd, P., De Pauw, E.: Comparison of Different Ion Mobility Setups Using Poly (Ethylene Oxide) PEO Polymers: Drift Tube, TIMS, and TWave. J. Am. Soc. Mass Spectrom. 29, 114-120 (2018)

42. Benigni, P., Sandoval, K., Thompson, C.J., Ridgeway, M.E., Park, M.A., Gardinali, P., Fernandez-Lima, F.: Analysis of Photoirradiated Water Accommodated Fractions of 
Crude Oils Using Tandem TIMS and FT-ICR MS. Environ. Sci. Technol. 51, 5978-5988 (2017)

43. Baglai, A., Gargano, A.F.G., Jordens, J., Mengerink, Y., Honing, M., van der Wal, S., Schoenmakers, P.J.: Comprehensive lipidomic analysis of human plasma using multidimensional liquid- and gas-phase separations: Two-dimensional liquid chromatography-mass spectrometry vs. liquid chromatography-trapped-ion-mobilitymass spectrometry. J. Chromatogr. A. 1530, 90-103 (2017)

44. Meier, F., Beck, S., Grassl, N., Lubeck, M., Park, M.A., Raether, O., Mann, M.: Parallel Accumulation-Serial Fragmentation (PASEF): Multiplying Sequencing Speed and Sensitivity by Synchronized Scans in a Trapped Ion Mobility Device. J. Proteome Res. 14, $5378-5387(2015)$

45. Meier, F., Brunner, A.D., Koch, S., Koch, H., Lubeck, M., Krause, M., Goedecke, N., Decker, J., Kosinski, T., Park, M.A., Bache, N., Hoerning, O., Cox, J., Rather, O., Mann, M.: Online parallel accumulation - serial fragmentation (PASEF) with a novel trapped ion mobility mass spectrometer. Mol. Cell. Proteomics. 17, 2534-2545 (2018)

46. Adams, K.J., Ramirez, C.E., Smith, N.F., Munoz-Munoz, A.C., Andrade, L., FernandezLima, F.: Analysis of isomeric opioids in urine using LC-TIMS-TOF MS. Talanta. 183, 177$183(2018)$

47. Garabedian, A., Baird, M.A., Porter, J., Jeanne Dit Fouque, K., Shliaha, P.V., Jensen, O.N., Williams, T.D., Fernandez-Lima, F., Shvartsburg, A.A.: Linear and Differential Ion Mobility Separations of Middle-Down Proteoforms. Anal. Chem. 9o, 2918-2925 (2018)

48. Jeanne Dit Fouque, K., Garabedian, A., Porter, J., Baird, M., Pang, X., Williams, T.D., Li, L., Shvartsburg, A., Fernandez-Lima, F.: Fast and Effective Ion Mobility-Mass Spectrometry Separation of d-Amino-Acid-Containing Peptides. Anal. Chem. 89, 11787$11794(2017)$ 
49. Dit Fouque, K.J., Moreno, J., Hegemann, J.D., Zirah, S., Rebuffat, S., Fernandez-Lima, F.: Identification of Lasso Peptide Topologies Using Native Nanoelectrospray IonizationTrapped Ion Mobility Spectrometry-Mass Spectrometry. Anal. Chem. 9o, 5139-5146 (2018)

5o. Jeanne Dit Fouque, K., Moreno, J., Hegemann, J.D., Zirah, S., Rebuffat, S., FernandezLima, F.: Metal ions induced secondary structure rearrangements: mechanically interlocked lasso vs. unthreaded branched-cyclic topoisomers. Analyst. 143, 2323-2333 (2018)

51. Salomon, R.A., Farias, R.N.: Microcin 25, a novel antimicrobial peptide produced by Escherichia coli. J. Bacteriol. 174, 7428-7435 (1992)

52. Solbiati, J.O., Ciaccio, M., Farias, R.N., Gonzalez-Pastor, J.E., Moreno, F., Salomon, R.A.: Sequence analysis of the four plasmid genes required to produce the circular peptide antibiotic microcin J25. J. Bacteriol. 181, 2659-2662 (1999)

53. McDaniel, E.W., Mason, E.A.: The mobility and diffusion of ions in gases. John Wiley and Sons, Inc., New York, New York (1973)

54. Pierson, N.A., Chen, L., Russell, D.H., Clemmer, D.E.: Cis-trans isomerizations of proline residues are key to bradykinin conformations. J. Am. Chem. Soc. 135, 3186-3192 (2013)

55. Dilger, J.M., Valentine, S.J., Glover, M.S., Ewing, M.A., Clemmer, D.E.: A database of alkali metal-containing peptide cross sections: Influence of metals on size parameters for specific amino acids. Int. J. Mass Spectrom. 330, 35-45 (2012)

56. Valentine, S.J., Counterman, A.E., Clemmer, D.E.: A database of 660 peptide ion cross sections: use of intrinsic size parameters for bona fide predictions of cross sections. J. Am. Soc. Mass Spectrom. 1o, 1188-1211 (1999)

57. Srebalus Barnes, C.A., Clemmer, D.E.: Assessing Intrinsic Side Chain Interactions between $\mathrm{i}$ and $\mathrm{i}+4$ Residues in Solvent-Free Peptides: A Combinatorial Gas-Phase Approach. J. Phys. Chem. A. 107, 10566-10579 (2003) 
58. Bush, M.F., Hall, Z., Giles, K., Hoyes, J., Robinson, C.V., Ruotolo, B.T.: Collision cross sections of proteins and their complexes: a calibration framework and database for gasphase structural biology. Anal. Chem. 82, 9557-9565 (2010)

59. Bush, M.F., Campuzano, I.D., Robinson, C.V.: Ion mobility mass spectrometry of peptide ions: effects of drift gas and calibration strategies. Anal. Chem. 84, 7124-7130 (2012)

6o. Romano, M., Fusco, G., Choudhury, H.G., Mehmood, S., Robinson, C.V., Zirah, S., Hegemann, J.D., Lescop, E., Marahiel, M.A., Rebuffat, S., De Simone, A., Beis, K.: Structural Basis for Natural Product Selection and Export by Bacterial ABC Transporters. ACS Chem. Biol. 13, 1598-1609 (2018)

61. Bayro, M.J., Mukhopadhyay, J., Swapna, G.V., Huang, J.Y., Ma, L.C., Sineva, E., Dawson, P.E., Montelione, G.T., Ebright, R.H.: Structure of antibacterial peptide microcin J25: a 21-residue lariat protoknot. J. Am. Chem. Soc. 125, 12382-12383 (2003)

62. Stewart, D.E., Sarkar, A., Wampler, J.E.: Occurrence and role ofcis peptide bonds in protein structures. J. Mol. Biol. 214, 253-260 (1990)

63. El-Baba, T.J., Fuller, D.R., Hales, D.A., Russell, D.H., Clemmer, D.E.: Solvent Mediation of Peptide Conformations: Polyproline Structures in Water, Methanol, Ethanol, and 1Propanol as Determined by Ion Mobility Spectrometry-Mass Spectrometry. J. Am. Soc. Mass Spectrom., DOI: 10.1007/s13361-018-2034-7 (2018)

64. Zhong, Y., Han, L., Ruotolo, B.T.: Collisional and Coulombic unfolding of gas-phase proteins: high correlation to their domain structures in solution. Angew. Chem. 53, 9209$9212(2014)$

65. Shi, H., Atlasevich, N., Merenbloom, S.I., Clemmer, D.E.: Solution dependence of the collisional activation of ubiquitin $[\mathrm{M}+7 \mathrm{H}](7+)$ ions. J. Am. Soc. Mass Spectrom. 25, 200o$2008(2014)$

66. Schenk, E.R., Ridgeway, M.E., Park, M.A., Leng, F., Fernandez-Lima, F.: Isomerization Kinetics of AT Hook Decapeptide Solution Structures. Anal. Chem. 86, 1210-1214 (2014) 
67. Molano-Arevalo, J.C., Hernandez, D.R., Gonzalez, W.G., Miksovska, J., Ridgeway, M.E., Park, M.A., Fernandez-Lima, F.: Flavin Adenine Dinucleotide structural motifs: from solution to gas-phase. Anal. Chem. 86, 10223-10230 (2014) 


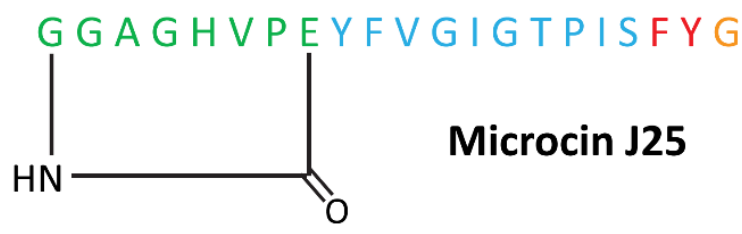

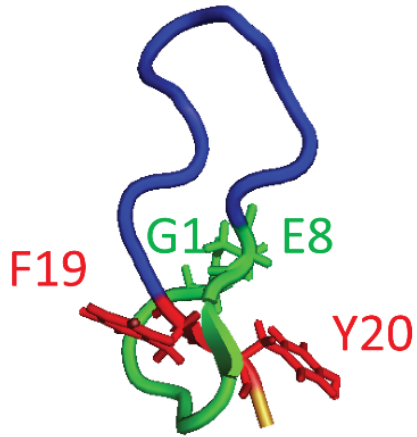

G21

Scheme 1. Sequence and three-dimensional structure of microcin J25 (PDB 1Q71) [19]. The macrolactam ring is colored in green, the loop in blue, the plugs in red and the Cterminal tail in orange. The Pro7 and Pro16 residues, located in the ring and loop respectively, are pointed in lighter green and blue colors. 
FIGURES

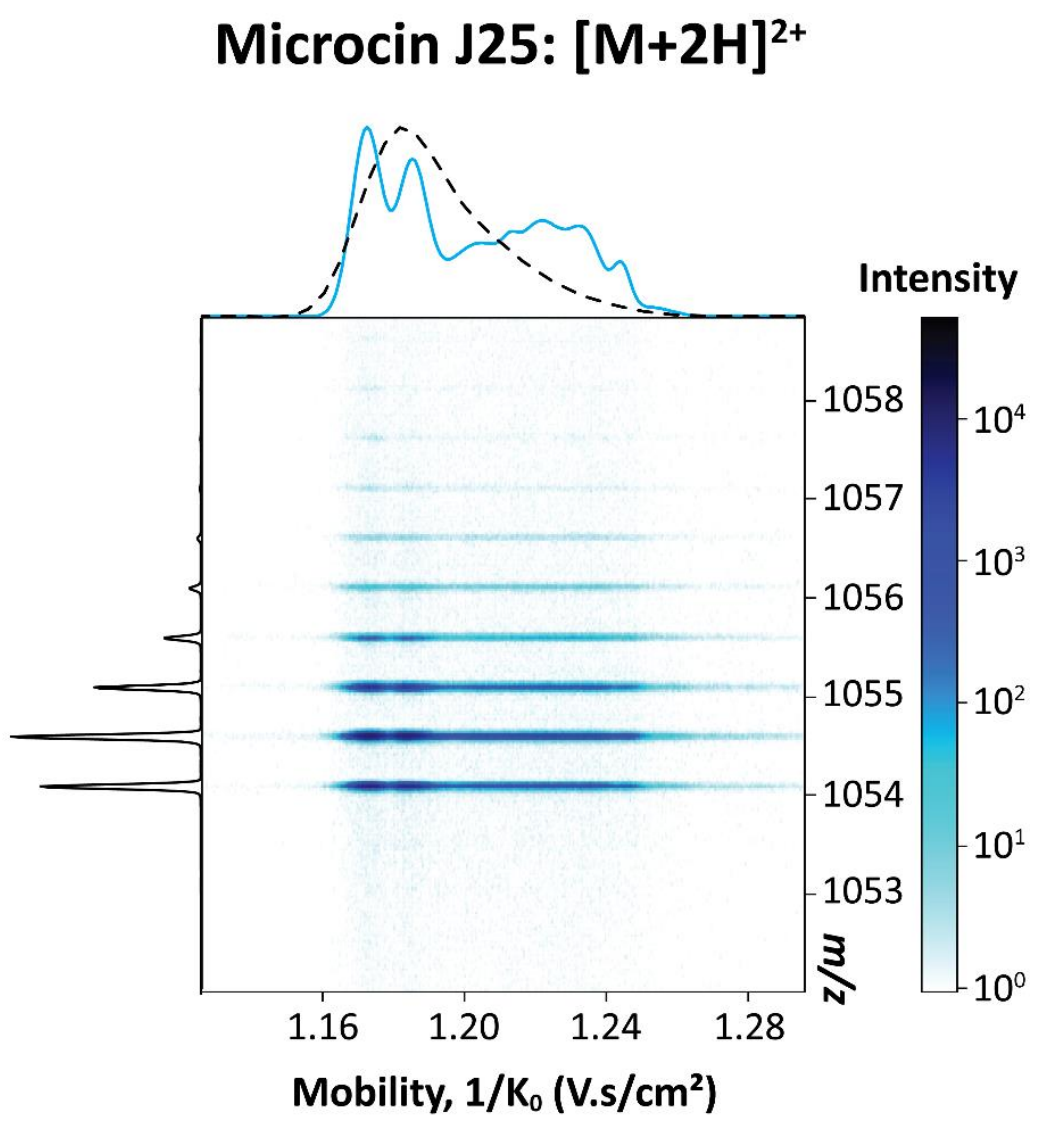

Figure 1. 2D-TIMS-MS contour map of the doubly protonated species of the lasso peptide microcin J25 WT under native conditions and no ion heating. The black dashed line illustrates a previously reported TWIMS distribution [25]. 
Microcin J25

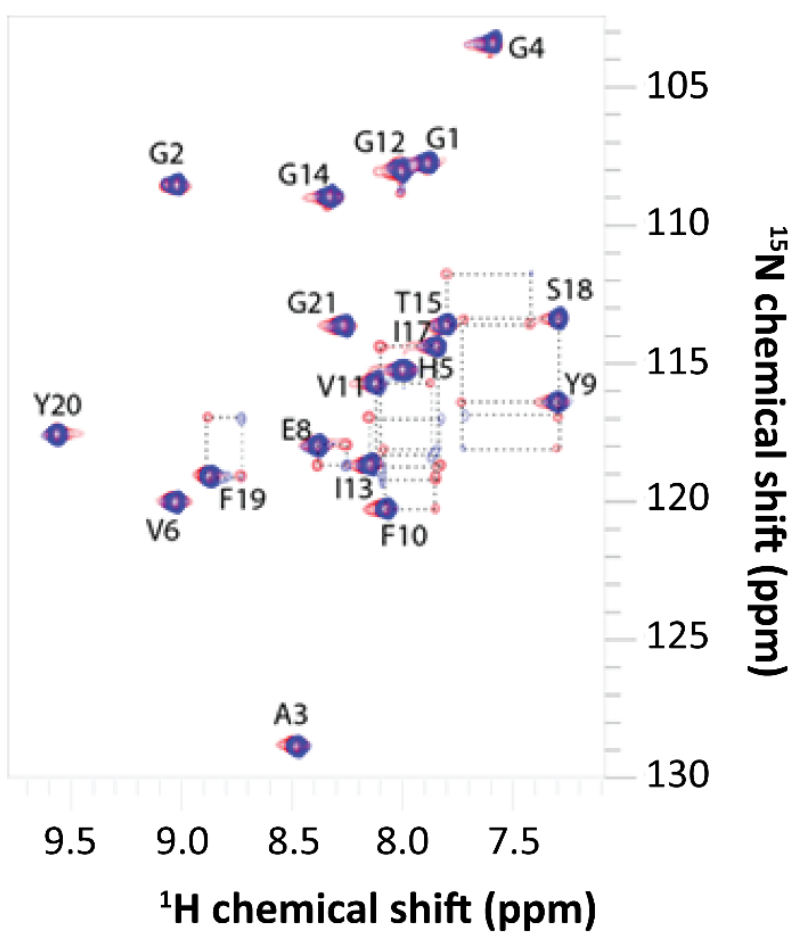

Figure 2. The ${ }^{15} \mathrm{~N}$ HSQC spectrum of ${ }^{15} \mathrm{~N}$ labeled microcin $\mathrm{J}_{25}$ in $\mathrm{CD}_{3} \mathrm{OH}$ is shown in blue. The spectrum shown in red is a ZZ-exchange spectrum with a mixing time of 600 ms. For clarity, the weak cross peaks corresponding to the minor conformation (cis) are not labeled. 
a) Microcin J25: $\mathrm{NH}_{4} \mathrm{AC}$

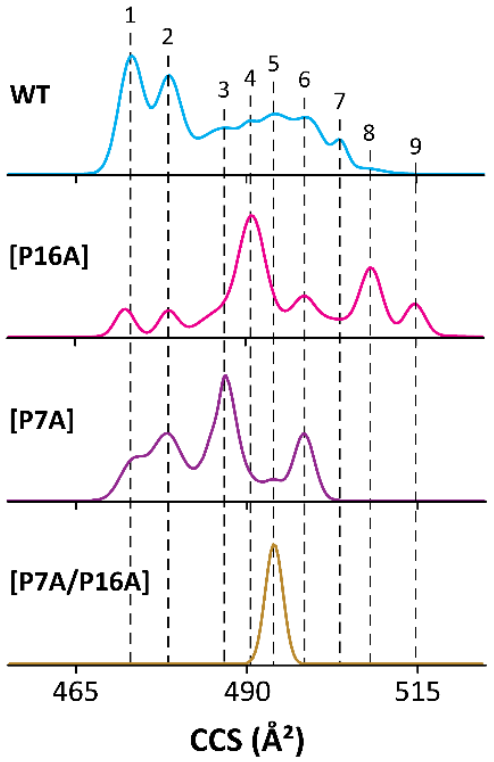

b) Microcin J25: 5:95 $\mathrm{H}_{2} \mathrm{O} / \mathrm{MeOH}$

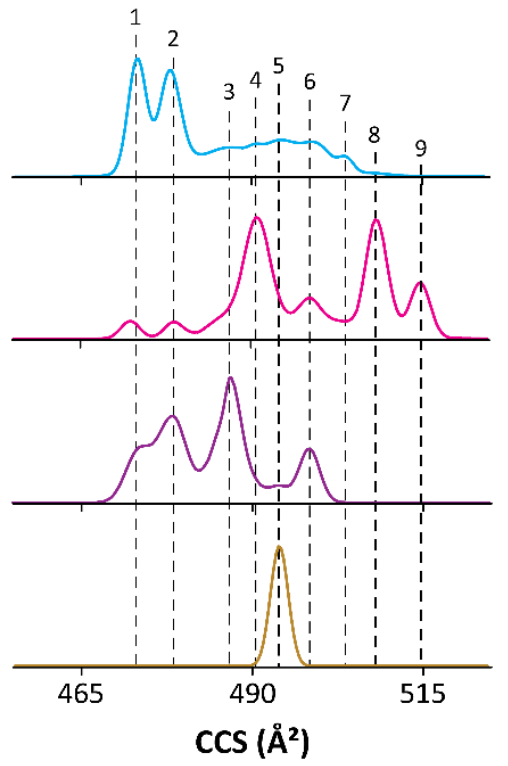

c) Microcin J25: $\Delta \mathrm{V}=\mathbf{3 0 0 \mathrm { V }}$

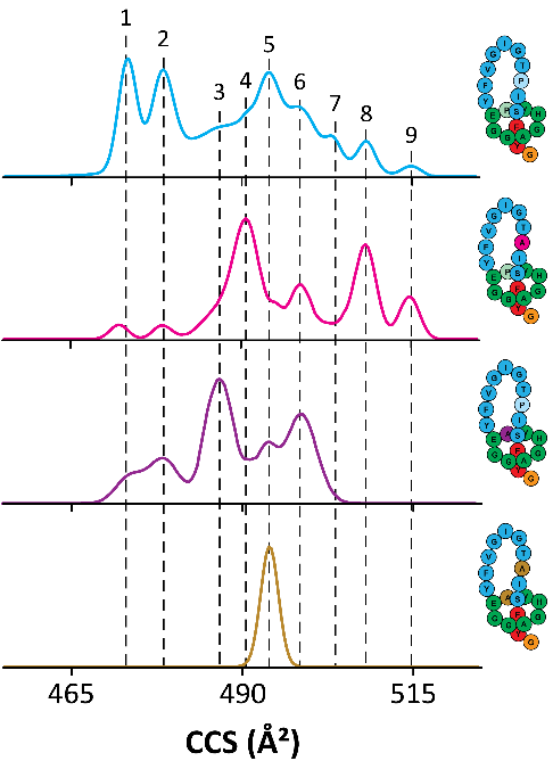

Figure 3. High resolution TIMS spectra for the $[\mathrm{M}+2 \mathrm{H}]^{2+}$ ions of microcin $\mathrm{J}_{25}$ (blue trace), the $[\mathrm{P} 16 \mathrm{~A}]$ variant (magenta trace), the $\left[\mathrm{P}_{7} \mathrm{~A}\right]$ variant (purple trace) and the $\left[\mathrm{P}_{7} \mathrm{~A} / \mathrm{P} 16 \mathrm{~A}\right]$ double variant (gold trace) in a) native condition $\left(\mathrm{NH}_{4} \mathrm{Ac}\right)$, denaturing condition $\left(5: 95 \mathrm{H}_{2} \mathrm{O} / \mathrm{MeOH}\right)$ and c) with an activation energy of $\Delta \mathrm{V}=300 \mathrm{~V} . \Delta \mathrm{V}$ represents the voltage difference between $V_{\text {def }}$ and $V_{\text {fun }}$ (Figure $S_{3}$ ). 
TABLES

Table 1. Summary of proline cis/trans-configuration at Pro7 and Pro16 peptide bonds of the native microcin J25 WT per IMS band (1-9).

\begin{tabular}{lll}
\hline \multirow{2}{*}{ IMS bands } & \multicolumn{2}{l}{ cis/trans-configurations } \\
& Pro7 & Pro16 \\
\hline 1 & cis/trans & trans/cis \\
2 & cis/trans & trans/cis \\
3 & trans & cis \\
4 & cis & trans \\
5 & trans & trans \\
6 & trans & trans \\
7 & cis & cis \\
8 & cis & trans \\
9 & cis & trans \\
\hline
\end{tabular}


GRAPHICAL ABSTRACT

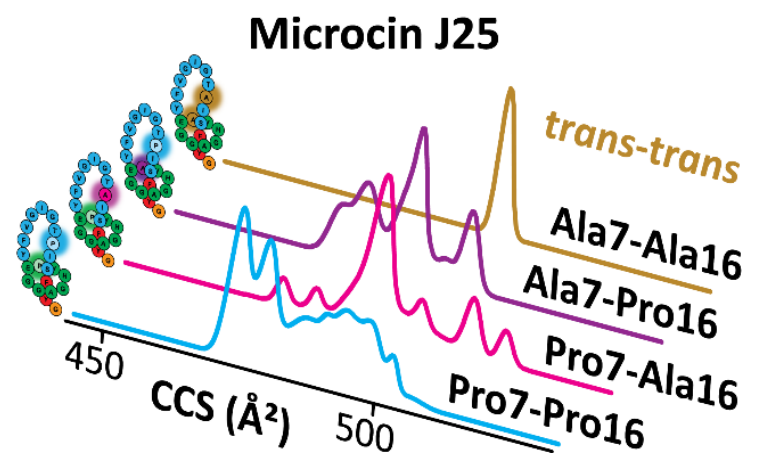

14

17

18

19

20

21

22

23

24

25

26

27

28

29

30

31

32

33

34

35

36

37

38

39

40

41

42

43

44

45

46

47

48

49

50

51

52

53

54

55

56

57

58

59

60

61

62 
Scheme 1. Sequence and three-dimensional structure of microcin J25 (PDB 1Q71) [19]. The macrolactam ring is colored in green, the loop in blue, the plugs in red and the Cterminal tail in orange. The Pro7 and Pro16 residues, located in the ring and loop respectively, are pointed in lighter green and blue colors.

Figure 1. 2D-TIMS-MS contour map of the doubly protonated species of the lasso peptide microcin J25 WT under native conditions and no ion heating. The black dashed line illustrates a previously reported TWIMS distribution [25].

Figure 2. The ${ }^{15} \mathrm{~N}$ HSQC spectrum of ${ }^{15} \mathrm{~N}$ labeled microcin $\mathrm{J}_{25}$ in $\mathrm{CD}_{3} \mathrm{OH}$ is shown in blue. The spectrum shown in red is a ZZ-exchange spectrum with a mixing time of 600 ms. For clarity, the weak cross peaks corresponding to the minor conformation (cis) are not labeled.

Figure 3. High resolution TIMS spectra for the $[\mathrm{M}+2 \mathrm{H}]^{2+}$ ions of microcin $\mathrm{J}_{25}$ (blue trace), the $[\mathrm{P} 16 \mathrm{~A}]$ variant (magenta trace), the $\left[\mathrm{P}_{7} \mathrm{~A}\right]$ variant (purple trace) and the $\left[\mathrm{P}_{7} \mathrm{~A} / \mathrm{P}_{16 \mathrm{~A}}\right]$ double variant (gold trace) in a) native condition $\left(\mathrm{NH}_{4} \mathrm{Ac}\right)$, denaturing condition $\left(5: 95 \mathrm{H}_{2} \mathrm{O} / \mathrm{MeOH}\right)$ and $\left.\mathrm{c}\right)$ with an activation energy of $\Delta \mathrm{V}=300 \mathrm{~V} . \Delta \mathrm{V}$ represents the voltage difference between $V_{\text {def }}$ and $V_{\text {fun }}$ (Figure $S_{3}$ ). 
Table 1. Summary of proline cis/trans-configuration at Pro7 and Pro16 peptide

1 bonds of the native microcin J25 WT per IMS band (1-9). 
Click here to access/download;Figures;Scheme 1 Isomerization MccJ25-01.tif $\underline{\underline{\bullet}}$
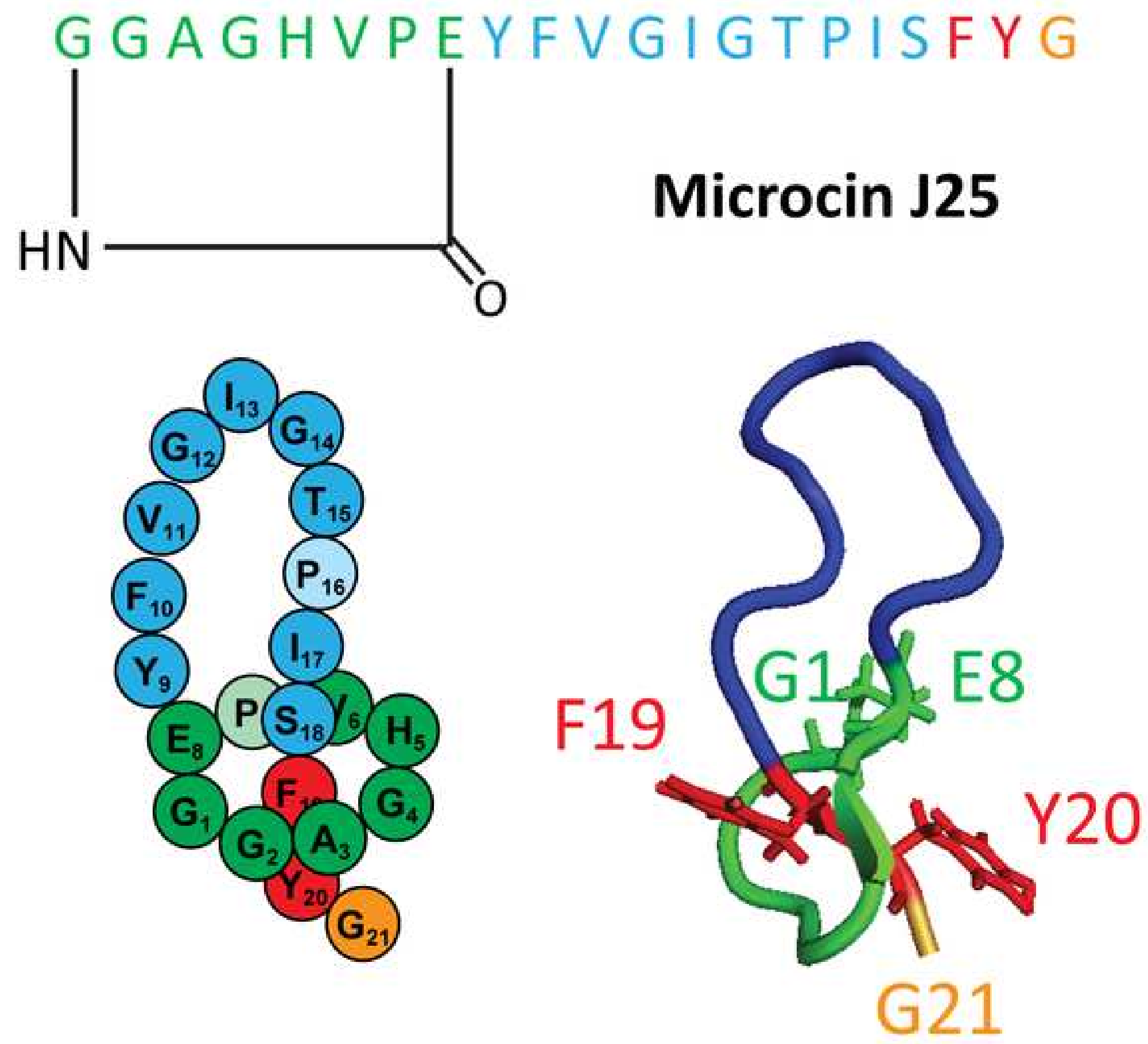


\section{Microcin J25: $[\mathrm{M}+2 \mathrm{H}]^{2+}$}

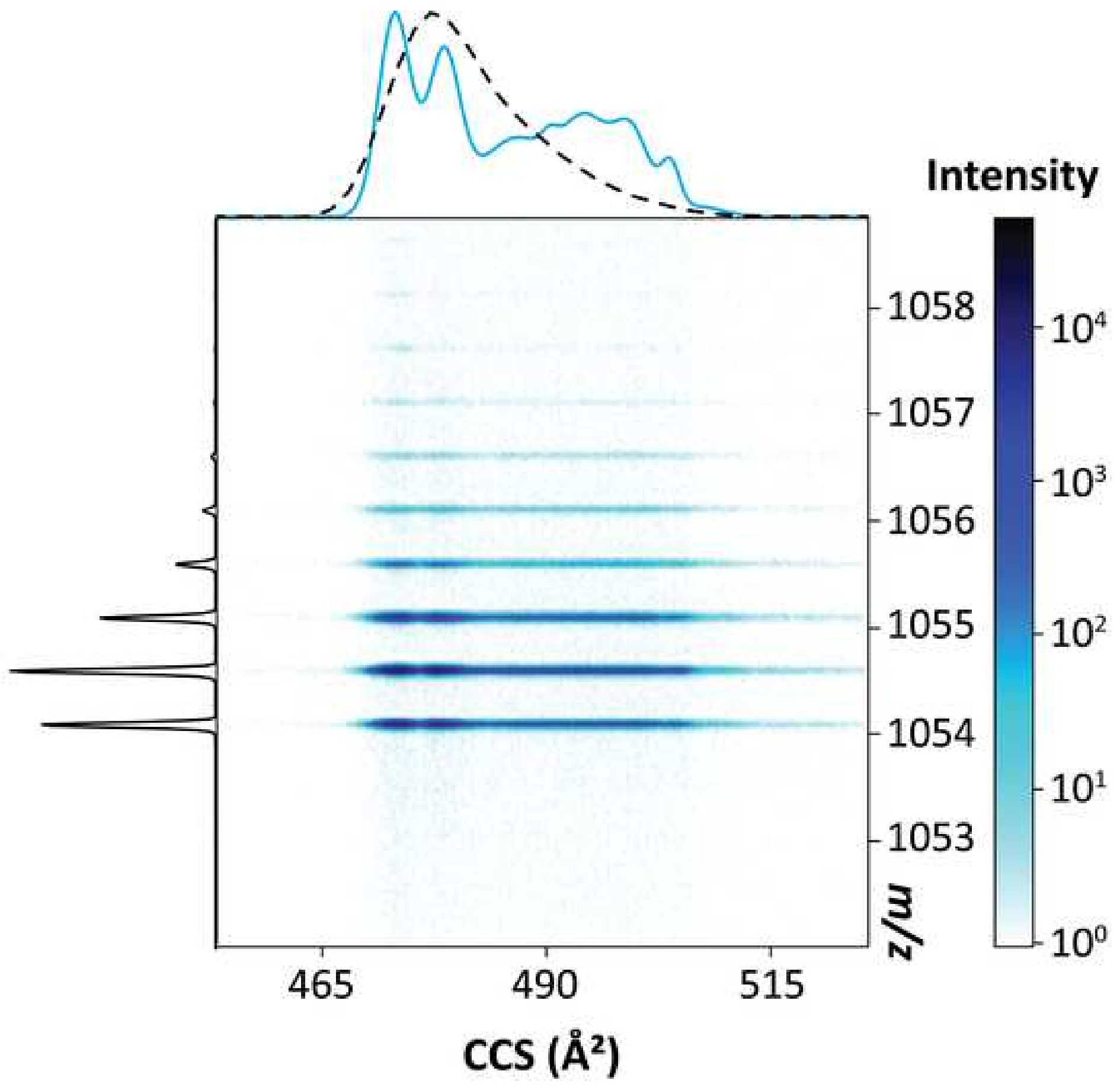




\section{Microcin J25}

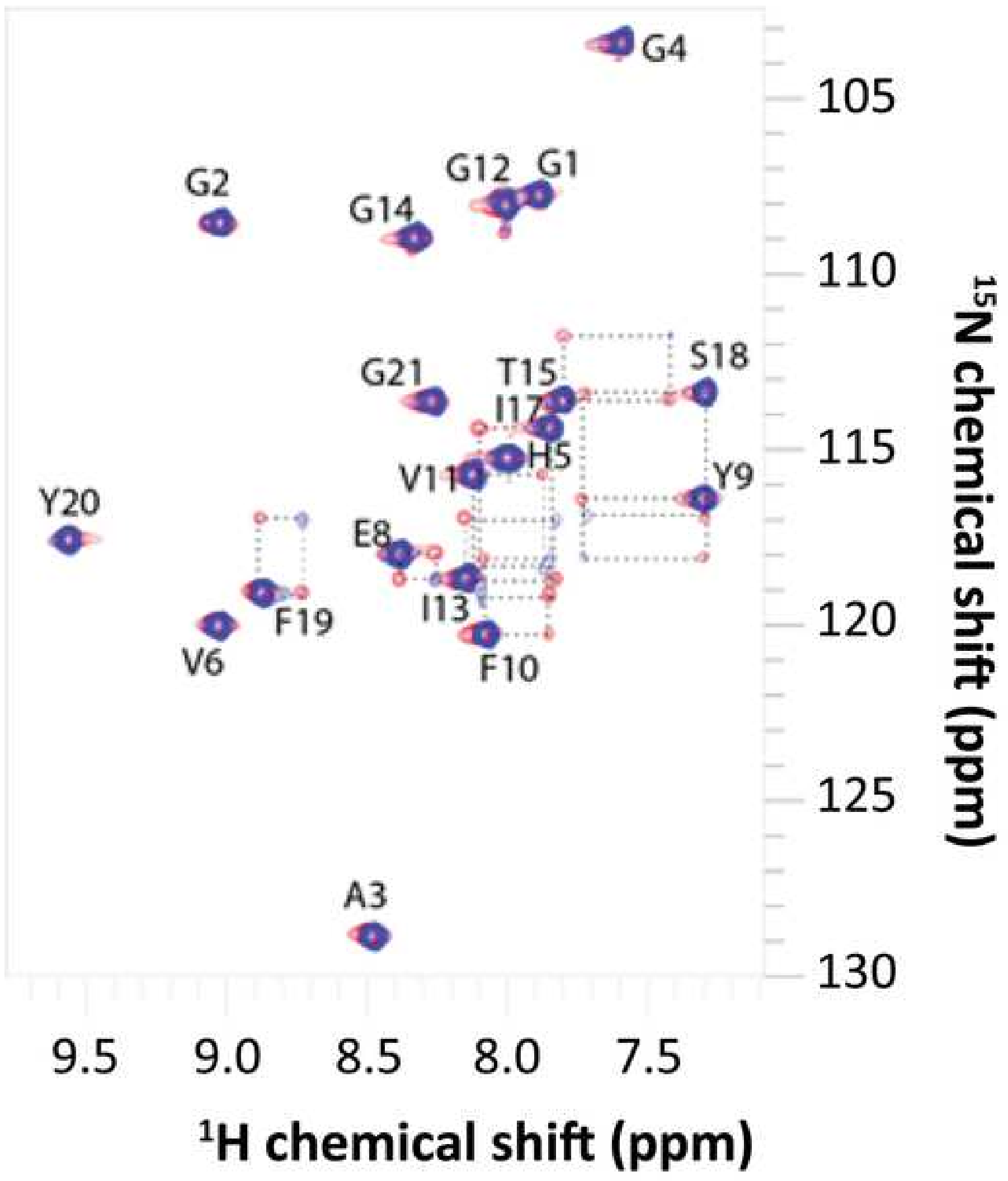

105

G2

G21

E8.

i1

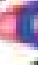

F

S18

130

\section{$\begin{array}{lllll}9.5 & 9.0 & 8.5 & 8.0 & 7.5\end{array}$




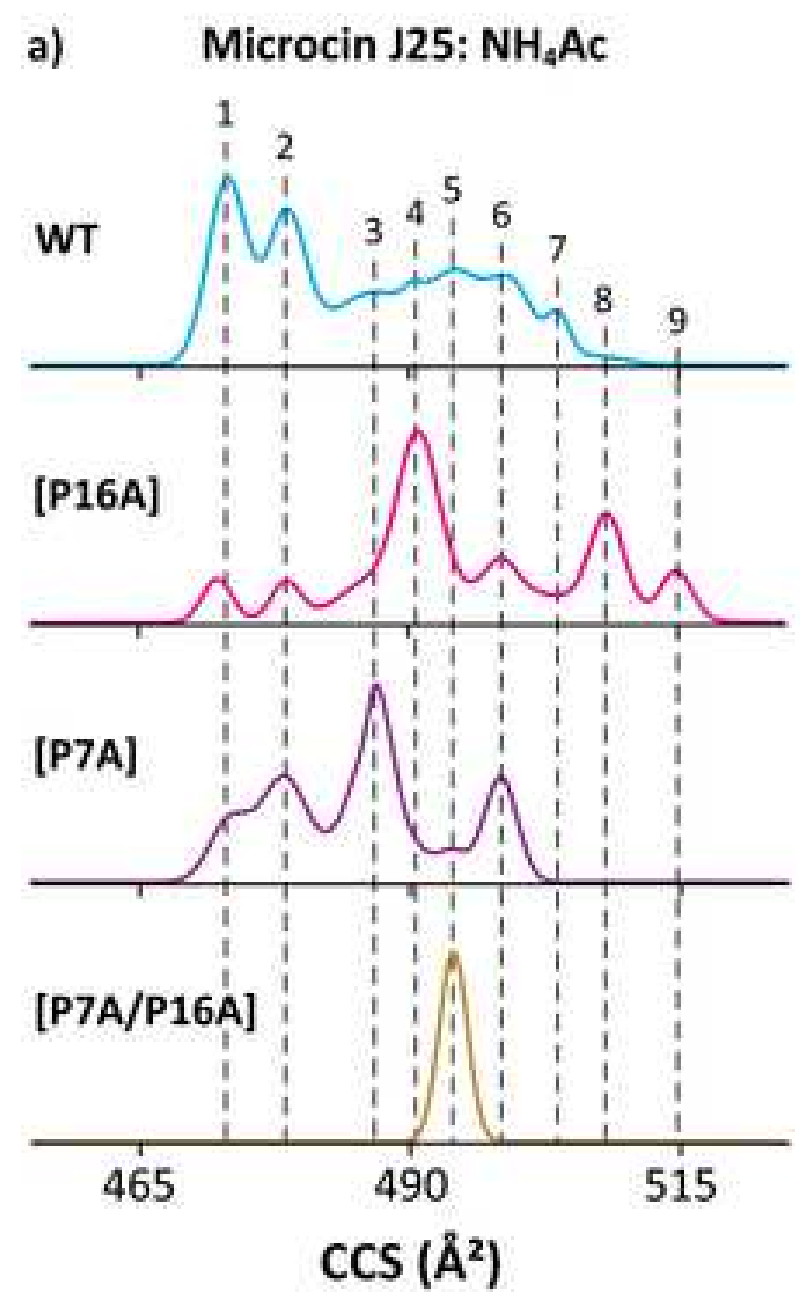

b) Microcin J25: 5:95 $\mathrm{H}_{2} \mathrm{O} / \mathrm{MeOH}$
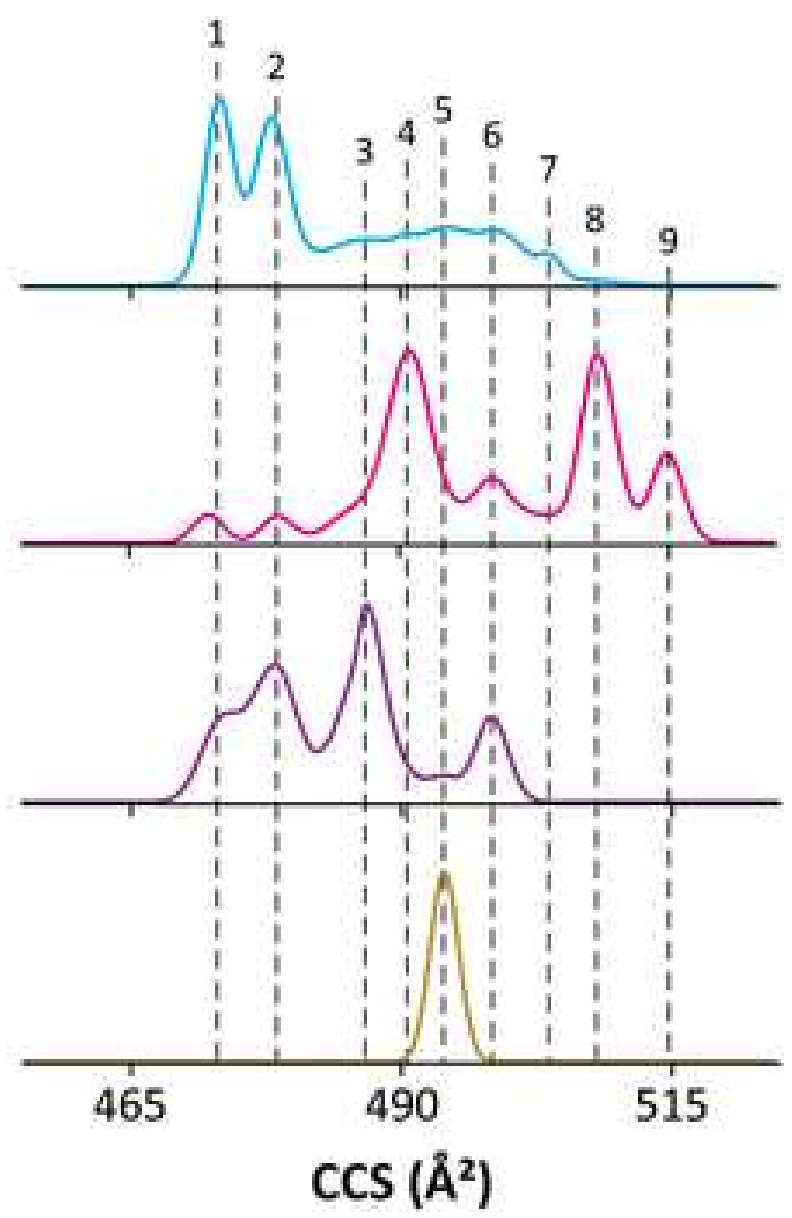

c) Microcin J25: $\Delta \mathrm{V}=300 \mathrm{~V}$

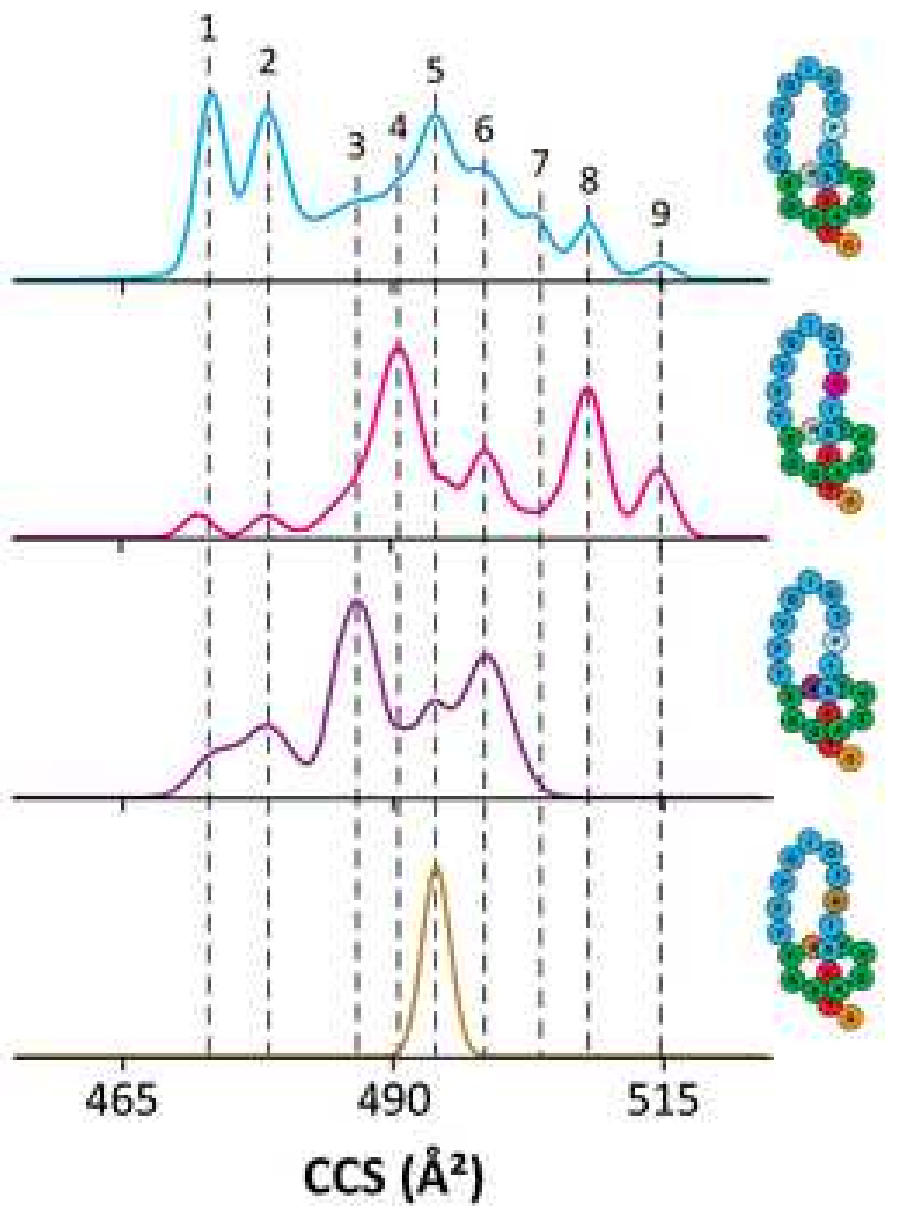




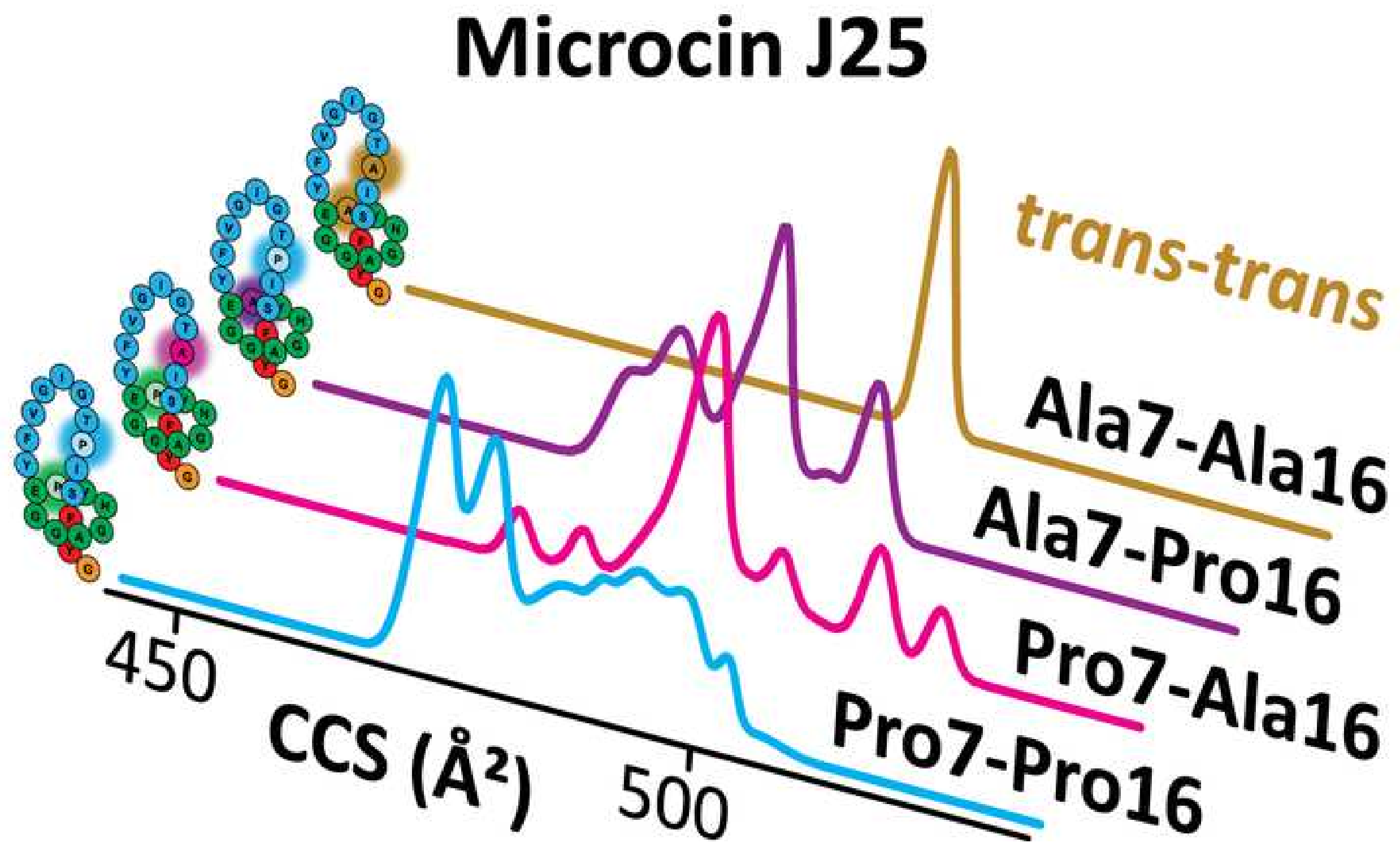


Click here to access/download Supplemental Information Lasso_Isomerization_SI_Final_Revised.docx 
Click here to access/download Supplemental Information manuscript revised with track changes.docx 